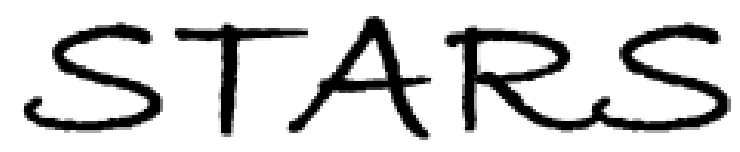

University of Central Florida

STARS

$1-1-1997$

\title{
Site-selective excitation and polarized absorption and emission spectra of trivalent thulium and erbium in strontium fluorapatite
}

John B. Gruber

Andrew 0. Wright

Michael D. Seltzer

Bahram Zandi

Larry D. Merkle

See next page for additional authors

Find similar works at: https://stars.library.ucf.edu/facultybib1990

University of Central Florida Libraries http://library.ucf.edu

This Article is brought to you for free and open access by the Faculty Bibliography at STARS. It has been accepted for inclusion in Faculty Bibliography 1990s by an authorized administrator of STARS. For more information, please contact STARS@ucf.edu.

\section{Recommended Citation}

Gruber, John B.; Wright, Andrew O.; Seltzer, Michael D.; Zandi, Bahram; Merkle, Larry D.; Hutchinson, J. Andrew; Morrison, Clyde A.; Allik, Toomas H.; and Chai, Bruce H. T., "Site-selective excitation and polarized absorption and emission spectra of trivalent thulium and erbium in strontium fluorapatite" (1997). Faculty Bibliography 1990s. 1930.

https://stars.library.ucf.edu/facultybib1990/1930

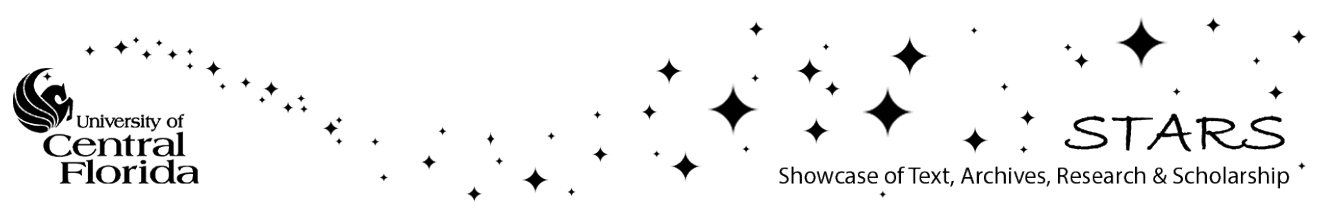




\section{Authors}

John B. Gruber, Andrew O. Wright, Michael D. Seltzer, Bahram Zandi, Larry D. Merkle, J. Andrew Hutchinson, Clyde A. Morrison, Toomas H. Allik, and Bruce H. T. Chai 


\section{Site-selective excitation and polarized absorption and emission spectra of trivalent thulium and erbium in strontium fluorapatite}

Cite as: Journal of Applied Physics 81, 6585 (1997); https://doi.org/10.1063/1.365197

Submitted: 09 October 1996. Accepted: 04 February 1997. Published Online: 17 August 1998

John B. Gruber, Andrew O. Wright, Michael D. Seltzer, Bahram Zandi, Larry D. Merkle, J. Andrew Hutchinson, Clyde A. Morrison, Toomas H. Allik, and Bruce H. T. Chai

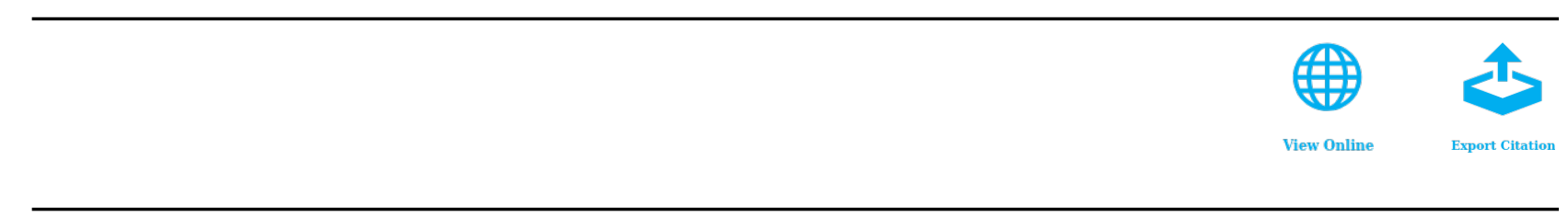

\section{ARTICLES YOU MAY BE INTERESTED IN}

Spectra and energy levels of trivalent holmium in strontium fluorapatite

Journal of Applied Physics 81, 7506 (1997); https://doi.org/10.1063/1.365292

Site-selective excitation and polarized absorption spectra of $\mathrm{Nd}^{3+}$ in $\mathrm{Sr}_{5}\left(\mathrm{PO}_{4}\right)_{3} \mathrm{~F}$ and $\mathrm{Ca}_{5}\left(\mathrm{PO}_{4}\right)_{3} \mathrm{~F}$

Journal of Applied Physics 79, 1746 (1996); https://doi.org/10.1063/1.360964

Crystal-field splitting of energy levels of rare-earth ions $\mathrm{Dy}^{3+}\left(4 \mathrm{f}^{9}\right)$ and $\mathrm{Yb}^{3+}\left(4 \mathrm{f}^{13}\right)$ in $\mathrm{M}(\mathrm{II})$ sites in the fluorapatite crystal $\mathrm{Sr}_{5}\left(\mathrm{PO}_{4}\right)_{3} \mathrm{~F}$

Journal of Applied Physics 83, 1009 (1998); https://doi.org/10.1063/1.366790

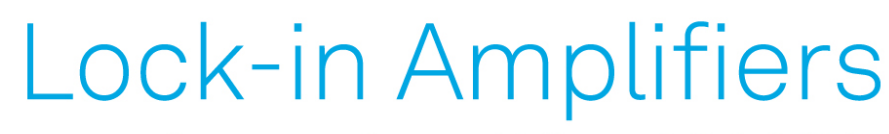
... and more, from DC to $600 \mathrm{MHz}$

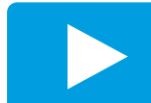

Watch 


\title{
Site-selective excitation and polarized absorption and emission spectra of trivalent thulium and erbium in strontium fluorapatite
}

\author{
John B. Gruber \\ Department of Physics, San José State University, San José, California 95192-0106
}

Andrew O. Wright and Michael D. Seltzer

Research and Technology Division, Naval Air Warfare Center, Code 474230D, China Lake, California 93555-6001

Bahram Zandi and Larry D. Merkle

IR Optics Technology OFC, Army Research Laboratory, Ft. Belvoir, Virginia 22060-5838

J. Andrew Hutchinson

Night Vision and Electronics Sensors Directorate, The United States Army, Ft. Belvoir, Virginia 22060-5806

Clyde A. Morrison

Army Research Laboratory, Adelphi, Maryland 20783-1145

Toomas H. Allik

Science Applications International Corporation, 1710 Goodridge Drive, McLean, Virginia 22102

Bruce H. T. Chai

Center for Research on Electro-optics and Lasers, University of Central Florida, Orlando, Florida 32836

(Received 9 October 1996; accepted for publication 4 February 1997)

\begin{abstract}
Polarized fluorescence spectra produced by site-selective excitation, and conventional polarized absorption spectra were obtained for $\mathrm{Tm}^{3+}$ and $\mathrm{Er}^{3+}$ ions individually incorporated into single crystals of strontium fluorapatite, $\mathrm{Sr}_{5}\left(\mathrm{PO}_{4}\right)_{3} \mathrm{~F}$, also known as SFAP. Substitution of the trivalent rare earth ion for divalent strontium was achieved by passive charge compensation during Czochralski growth of the fluorapatite crystals. Spectra were obtained between 1780 and $345 \mathrm{~nm}$ at temperatures from $4 \mathrm{~K}$ to room temperature on crystals having the hexagonal structure $\left[P 6_{3} / m\left(C_{6 h}^{2}\right)\right]$. The polarized fluorescence spectra due to transitions from multiplet manifolds of $\mathrm{Tm}^{3+}\left(4 f^{12}\right)$, including ${ }^{1} \mathrm{D}_{2},{ }^{1} \mathrm{G}_{4}$, and ${ }^{3} \mathrm{H}_{4}$ to manifolds ${ }^{3} \mathrm{H}_{6}$ (the ground-state manifold), ${ }^{3} \mathrm{~F}_{4},{ }^{3} \mathrm{H}_{5},{ }^{3} \mathrm{H}_{4}$, and ${ }^{3} \mathrm{~F}_{3}$ were analyzed for the details of the crystal-field splitting of the manifolds. Fluorescence lifetimes were measured for $\mathrm{Tm}^{3+}$ transitions from ${ }^{1} \mathrm{D}_{2},{ }^{1} \mathrm{G}_{4}$, and ${ }^{3} \mathrm{H}_{4}$ at room temperature and from ${ }^{1} \mathrm{G}_{4}$ at $16 \mathrm{~K}$. Results of the analysis indicate that the majority of $\mathrm{Tm}^{3+}$ ions occupy sites having $C_{s}$ symmetry. A point-charge lattice-sum calculation was made in which the crystal-field components, $A_{n m}$, were determined assuming that trivalent thulium replaces divalent strontium in the metal site having $C_{s}$ symmetry. Results support the conclusion that the nearest-neighbor fluoride $\left(\mathrm{F}^{-}\right)$is replaced by divalent oxygen $\left(\mathrm{O}^{2-}\right)$, thus preserving overall charge neutrality and local symmetry. Crystal-field splitting calculations predict energy levels in agreement with results obtained from an analysis of the experimental data. By varying the crystal-field parameters, $B_{n m}$, we obtained a rms difference of $7 \mathrm{~cm}^{-1}$ between 43 calculated and experimental Stark levels for $\operatorname{Tm}^{3+}\left(4 f^{12}\right)$ in Tm:SFAP. Absorption and fluorescence spectra are also reported for $\mathrm{Er}^{3+}$ ions in Er:SFAP. Measurement of the temporal decay of the room temperature fluorescence from the ${ }^{4} \mathrm{I}_{11 / 2}$ and ${ }^{4} \mathrm{I}_{13 / 2}$ manifolds yielded fluorescence lifetimes of $230 \pm 20 \mu$ s and $8.9 \pm 0.1 \mathrm{~ms}$, respectively. The experimental Stark levels obtained from an analysis of the spectroscopic data were compared with a crystal-field splitting calculation. The initial set of $B_{n m}$ parameters for $\operatorname{Er}^{3+}\left(4 f^{11}\right)$ was established from the three-parameter theory and the final set of $B_{n m}$ parameters obtained for $\mathrm{Tm}^{3+}\left(4 f^{12}\right)$ in Tm:SFAP. The best overall agreement between calculated and experimental Stark levels is $8 \mathrm{~cm}^{-1}$ for 48 Stark levels, representing 12 observed multiplet manifolds of $\mathrm{Er}^{3+}\left(4 f^{11}\right)$ in Er:SFAP. (C) 1997 American Institute of Physics. [S0021-8979(97)01110-9]
\end{abstract}

\section{INTRODUCTION}

As a crystalline host for trivalent rare earth ions $\left(\mathrm{R}^{3+}\right)$, strontium fluorapatite $\left[\mathrm{Sr}_{5}\left(\mathrm{PO}_{4}\right)_{3} \mathrm{~F}\right]$, known as SFAP, has received growing attention as a laser host material or as a host for saturable Q-switch absorbers. ${ }^{1-3}$ An expanding number of applications point to its excellent spectroscopic and physical properties. ${ }^{4-6}$ This interest has been encouraged both by the size and optical quality of the crystals grown in recent years and by the development of diode pumping technology. A recent symposium on novel laser materials included a discussion on the advanced technology and applications for fluorapatites as host materials. ${ }^{7}$

In recent years details of the crystal-field splitting of energy levels of $\mathrm{R}^{3+}$ dopants such as $\mathrm{Pr}^{3+}, \mathrm{Nd}^{3+}, \mathrm{Eu}^{3+}$, and 
TABLE I. Absorption spectrum of $\mathrm{Tm}^{3+}$ in $\mathrm{Sr}_{5}\left(\mathrm{PO}_{4}\right)_{3} \mathrm{~F}$ at $4 \mathrm{~K}^{\mathrm{a}}$

\begin{tabular}{|c|c|c|c|c|c|c|c|c|c|c|c|}
\hline \multirow{2}{*}{$\frac{{ }^{2 S+1} \mathrm{~L}_{J}{ }^{\mathrm{b}}}{{ }^{3} \mathrm{~F}_{4}}$} & \multirow{2}{*}{$\frac{\lambda(\AA)^{\mathrm{c}}}{17729}$} & \multirow{2}{*}{$\frac{\alpha^{\mathrm{d}}}{0.20}$} & \multirow{2}{*}{$\frac{E\left(\mathrm{~cm}^{-1}\right)_{\mathrm{obs}}{ }^{\mathrm{e}}}{5639^{\mathrm{i}^{*}}}$} & \multirow{2}{*}{$\frac{E\left(\mathrm{~cm}^{-1}\right)_{\mathrm{calc}}^{\mathrm{f}}}{5646}$} & \multirow{2}{*}{$\frac{\Gamma_{n}^{\text {calc g }}}{2}$} & \multicolumn{6}{|c|}{ Percent free-ion mixture ${ }^{\mathrm{h}}$} \\
\hline & & & & & & 99.3 & ${ }^{3} \mathrm{~F}_{4}$ & +0.41 & ${ }^{3} \mathrm{H}_{6}$ & +0.14 & ${ }^{3} \mathrm{H}_{5}$ \\
\hline & 17610 & 0.40 & $5677^{i^{*}}$ & 5719 & 1 & 98.9 & ${ }^{3} \mathrm{~F}_{4}$ & +0.50 & ${ }^{3} \mathrm{H}_{5}$ & +0.47 & ${ }^{3} \mathrm{H}_{6}$ \\
\hline \multirow[t]{10}{*}{$(6000)$} & 17487 & 0.05 & 5717 & & & & & & & & \\
\hline & 16963 & 0.10 & 5894 & & & & & & & & \\
\hline & 16915 & 0.38 & $5910^{\mathrm{i}^{*}}$ & 5909 & 1 & 98.1 & ${ }^{3} \mathrm{~F}_{4}$ & +1.19 & ${ }^{3} \mathrm{H}_{5}$ & +0.54 & ${ }^{3} \mathrm{H}_{6}$ \\
\hline & 16828 & 0.05 & 5941 & 5918 & 2 & 96.8 & ${ }^{3} \mathrm{~F}_{4}$ & +2.78 & ${ }^{3} \mathrm{H}_{5}$ & +0.23 & ${ }^{3} \mathrm{H}_{6}$ \\
\hline & 16765 & 0.04 & $5963^{\mathrm{i}^{*}}$ & 5970 & 1 & 98.7 & ${ }^{3} \mathrm{~F}_{4}$ & +0.98 & ${ }^{3} \mathrm{H}_{5}$ & +0.16 & ${ }^{3} \mathrm{H}_{4}$ \\
\hline & 16732 & 0.11 & $5975^{\mathrm{i}^{*}}$ & 5976 & 2 & 97.5 & ${ }^{3} \mathrm{~F}_{4}$ & +1.81 & ${ }^{3} \mathrm{H}_{5}$ & +0.54 & ${ }^{3} \mathrm{H}_{6}$ \\
\hline & 16256 & 0.16 & $6150^{\mathrm{i}^{*}}$ & 6137 & 1 & 98.3 & ${ }^{3} \mathrm{~F}_{4}$ & +0.86 & ${ }^{3} \mathrm{H}_{6}$ & +0.62 & ${ }^{3} \mathrm{H}_{5}$ \\
\hline & 16128 & 0.80 & $6199^{i^{*}}$ & 6205 & 2 & 98.0 & ${ }^{3} \mathrm{~F}_{4}$ & +1.05 & ${ }^{3} \mathrm{H}_{5}$ & +0.75 & ${ }^{3} \mathrm{H}_{6}$ \\
\hline & 16065 & 0.05 & 6223 & & & & & & & & \\
\hline & 15991 & 0.60 & $6252^{\mathrm{i}^{*}}$ & 6245 & 1 & 97.6 & ${ }^{3} \mathrm{~F}_{4}$ & +1.91 & ${ }^{3} \mathrm{H}_{5}$ & +0.22 & ${ }^{3} \mathrm{H}_{4}$ \\
\hline \multirow[t]{2}{*}{${ }^{3} \mathrm{H}_{5}$} & 12175 & 0.62 & $8211^{\mathrm{i}^{*}}$ & 8207 & 2 & 99.2 & ${ }^{3} \mathrm{H}_{5}$ & +0.45 & ${ }^{3} \mathrm{~F}_{3}$ & +0.16 & ${ }^{3} \mathrm{~F}_{4}$ \\
\hline & 12170 & 0.30 & $8213^{\mathrm{i}^{*}}$ & 8215 & 1 & 99.2 & ${ }^{3} \mathrm{H}_{5}$ & +0.48 & ${ }^{3} \mathrm{~F}_{3}$ & +0.15 & ${ }^{3} \mathrm{~F}_{4}$ \\
\hline \multirow[t]{12}{*}{$(8647)$} & 12 044(b) & 0.17 & $8301 *$ & 8303 & 1 & 98.5 & ${ }^{3} \mathrm{H}_{5}$ & +0.86 & ${ }^{3} \mathrm{~F}_{4}$ & +0.38 & ${ }^{3} \mathrm{~F}_{3}$ \\
\hline & $12025(\mathrm{sh})$ & 0.10 & 8314 & & & & & & & & \\
\hline & 11970 & 0.03 & $8352^{\mathrm{i}^{*}}$ & 8352 & 2 & 99.0 & ${ }^{3} \mathrm{H}_{5}$ & +0.54 & ${ }^{3} \mathrm{~F}_{3}$ & +0.34 & ${ }^{3} \mathrm{~F}_{4}$ \\
\hline & 11886 & 0.03 & $8410^{\mathrm{i} *}$ & 8405 & 2 & 99.2 & ${ }^{3} \mathrm{H}_{5}$ & +0.25 & ${ }^{3} \mathrm{~F}_{3}$ & +0.21 & ${ }^{3} \mathrm{~F}_{4}$ \\
\hline & 11851 & 0.05 & $8436^{i^{*}}$ & 8441 & 1 & 98.6 & ${ }^{3} \mathrm{H}_{5}$ & +0.67 & ${ }^{3} \mathrm{~F}_{4}$ & +0.43 & ${ }^{3} \mathrm{~F}_{3}$ \\
\hline & 11810 & 0.02 & $8465^{*}$ & & & & & & & & \\
\hline & 11651 & 0.01 & 8581 & & & & & & & & \\
\hline & 11451 & 0.02 & $8730^{\mathrm{i}^{*}}$ & 8731 & 2 & 96.0 & ${ }^{3} \mathrm{H}_{5}$ & +3.48 & ${ }^{3} \mathrm{~F}_{4}$ & +0.19 & ${ }^{3} \mathrm{H}_{4}$ \\
\hline & $11270(b)$ & 0.01 & 8870 & 8868 & 1 & 97.5 & ${ }^{3} \mathrm{H}_{5}$ & +1.66 & ${ }^{3} \mathrm{~F}_{4}$ & +0.30 & ${ }^{3} \mathrm{~F}_{2}$ \\
\hline & $11170(b)$ & 0.01 & 8950 & 8945 & 1 & 97.6 & ${ }^{3} \mathrm{H}_{5}$ & +1.69 & ${ }^{3} \mathrm{~F}_{4}$ & +0.39 & ${ }^{3} \mathrm{H}_{4}$ \\
\hline & $10715(b)$ & 0.01 & 9330 & 9321 & 2 & 98.8 & ${ }^{3} \mathrm{H}_{5}$ & +0.52 & ${ }^{3} \mathrm{~F}_{4}$ & +0.40 & ${ }^{3} \mathrm{~F}_{2}$ \\
\hline & & & & 9339 & 2 & 98.5 & ${ }^{3} \mathrm{H}_{5}$ & +0.89 & ${ }^{3} \mathrm{~F}_{4}$ & +0.25 & ${ }^{3} \mathrm{~F}_{2}$ \\
\hline \multirow[t]{2}{*}{${ }^{3} \mathrm{H}_{4}$} & 7943.2 & 4.25 & $12586^{\mathrm{i}^{*}}$ & 12586 & 2 & 97.8 & ${ }^{3} \mathrm{H}_{4}$ & +0.89 & ${ }^{3} \mathrm{~F}_{3}$ & +0.87 & ${ }^{3} \mathrm{~F}_{2}$ \\
\hline & 7937.5 & 3.64 & $12595^{\mathrm{i}^{*}}$ & 12595 & 1 & 99.0 & ${ }^{3} \mathrm{H}_{4}$ & +0.58 & ${ }^{3} \mathrm{~F}_{3}$ & +0.18 & ${ }^{3} \mathrm{~F}_{2}$ \\
\hline \multirow[t]{11}{*}{ (12 910) } & 7922.8 & 0.23 & 12618 & & & & & & & & \\
\hline & 7913.3 & 3.18 & $12633^{\mathrm{i}^{*}}$ & 12635 & 1 & 98.0 & ${ }^{3} \mathrm{H}_{4}$ & +1.47 & ${ }^{3} \mathrm{~F}_{3}$ & +0.18 & ${ }^{3} \mathrm{~F}_{2}$ \\
\hline & 7893.9 & 0.15 & 12665 & & & & & & & & \\
\hline & 7880.8 & 1.18 & $12686^{\mathrm{i}^{*}}$ & 12681 & 2 & 98.7 & ${ }^{3} \mathrm{H}_{4}$ & +0.94 & ${ }^{3} \mathrm{~F}_{3}$ & +0.23 & ${ }^{3} \mathrm{H}_{5}$ \\
\hline & 7857.9 & 0.76 & $12723^{\mathrm{i}}$ & 12726 & 1 & 97.8 & ${ }^{3} \mathrm{H}_{4}$ & +1.52 & ${ }^{3} \mathrm{~F}_{2}$ & +0.27 & ${ }^{3} \mathrm{H}_{5}$ \\
\hline & 7848(sh) & 0.06 & 12740 & 12740 & 2 & 97.1 & ${ }^{3} \mathrm{H}_{4}$ & +1.68 & ${ }^{3} \mathrm{~F}_{2}$ & +0.81 & ${ }^{3} \mathrm{~F}_{3}$ \\
\hline & 7809 (b) & .02 & 12802 & & & & & & & & \\
\hline & 7753.9 & .01 & 12893 & & & & & & & & \\
\hline & 7553(b) & 0.05 & 13236 & 13230 & 2 & 96.0 & ${ }^{3} \mathrm{H}_{4}$ & +3.22 & ${ }^{3} \mathrm{~F}_{3}$ & +0.27 & ${ }^{3} \mathrm{~F}_{2}$ \\
\hline & $7525(\mathrm{sh})$ & 0.08 & 13285 & 13266 & 1 & 95.0 & ${ }^{3} \mathrm{H}_{4}$ & +4.21 & ${ }^{3} \mathrm{~F}_{3}$ & +0.23 & ${ }^{3} \mathrm{~F}_{2}$ \\
\hline & 7519.1 & 0.26 & 13296 & 13320 & 1 & 94.0 & ${ }^{3} \mathrm{H}_{4}$ & +4.44 & ${ }^{3} \mathrm{~F}_{3}$ & +0.98 & ${ }^{3} \mathrm{~F}_{2}$ \\
\hline \multirow[t]{2}{*}{${ }^{3} F_{3}$} & 6958.3 & 0.07 & $14367^{*}$ & & & & & & & & \\
\hline & 6939.2 & 1.33 & $14407^{i^{*}}$ & 14397 & 2 & 98.5 & ${ }^{3} \mathrm{~F}_{3}$ & +1.13 & ${ }^{3} \mathrm{H}_{4}$ & +0.13 & ${ }^{3} \mathrm{H}_{5}$ \\
\hline \multirow[t]{7}{*}{$(14675)$} & 6918.0 & 0.05 & 14451 & & & & & & & & \\
\hline & 6811.2 & 0.42 & $14677^{i^{*}}$ & 14668 & 1 & 97.5 & ${ }^{3} \mathrm{~F}_{3}$ & +1.42 & ${ }^{3} \mathrm{H}_{4}$ & +0.39 & ${ }^{3} \mathrm{~F}_{2}$ \\
\hline & 6807.4 & 0.32 & $14688^{i^{*}}$ & 14693 & 2 & 96.9 & ${ }^{3} \mathrm{~F}_{3}$ & +2.39 & ${ }^{3} \mathrm{H}_{4}$ & +0.37 & ${ }^{3} \mathrm{~F}_{2}$ \\
\hline & 6769.0 & 0.04 & 14769 & 14775 & 1 & 93.0 & ${ }^{3} \mathrm{~F}_{3}$ & +5.67 & ${ }^{3} \mathrm{H}_{4}$ & +0.48 & ${ }^{3} \mathrm{~F}_{2}$ \\
\hline & 6752.9 & 0.42 & $14804^{\mathrm{i}^{*}}$ & 14816 & 2 & 97.1 & ${ }^{3} \mathrm{~F}_{3}$ & +1.68 & ${ }^{3} \mathrm{H}_{4}$ & +0.60 & ${ }^{3} \mathrm{H}_{5}$ \\
\hline & 6731.1 & 0.48 & $14852^{\mathrm{i}^{*}}$ & 14859 & 1 & 93.6 & ${ }^{3} \mathrm{~F}_{3}$ & +3.02 & ${ }^{3} \mathrm{H}_{4}$ & +2.48 & ${ }^{3} \mathrm{~F}_{2}$ \\
\hline & 6717.2 & 0.08 & $14883^{\mathrm{i}^{*}}$ & 14879 & 2 & 98.3 & ${ }^{3} \mathrm{~F}_{3}$ & +0.59 & ${ }^{3} \mathrm{H}_{5}$ & +0.52 & ${ }^{3} \mathrm{H}_{4}$ \\
\hline${ }^{3} \mathrm{~F}_{2}$ & 6405.8 & 0.03 & $15607^{\mathrm{i}}$ & 15600 & 1 & 95.9 & ${ }^{3} \mathrm{~F}_{2}$ & +2.05 & ${ }^{3} \mathrm{~F}_{3}$ & +1.65 & ${ }^{3} \mathrm{H}_{4}$ \\
\hline
\end{tabular}




\begin{tabular}{|c|c|c|c|c|c|c|c|c|c|c|c|}
\hline${ }^{2 S+1} \mathrm{~L}_{J}^{\mathrm{b}}$ & $\lambda(\AA)^{c}$ & $\alpha^{\mathrm{d}}$ & $E\left(\mathrm{~cm}^{-1}\right)_{\mathrm{obs}} \mathrm{e}^{\mathrm{e}}$ & $E\left(\mathrm{~cm}^{-1}\right)_{\text {calc }}{ }^{\mathrm{f}}$ & $\Gamma_{n}^{\text {calc g }}$ & & & rcent fre & $\operatorname{mix}$ & & \\
\hline \multirow{4}{*}{ (15 846) } & 6389.9 & 0.20 & $15645^{\mathrm{i}}$ & 15652 & 1 & 99.0 & ${ }^{3} \mathrm{~F}_{2}$ & +0.37 & ${ }^{3} \mathrm{H}_{4}$ & +0.26 & ${ }^{3} \mathrm{~F}_{3}$ \\
\hline & $6243(b)$ & 0.01 & 16014 & 16024 & 2 & 97.1 & ${ }^{3} \mathrm{~F}_{2}$ & +1.77 & ${ }^{3} \mathrm{H}_{4}$ & +0.63 & ${ }^{3} \mathrm{~F}_{3}$ \\
\hline & $6206(\mathrm{sh})$ & 0.01 & 16109 & 16110 & 1 & 97.4 & ${ }^{3} \mathrm{~F}_{2}$ & +1.64 & ${ }^{3} \mathrm{H}_{4}$ & +0.46 & ${ }^{3} \mathrm{~F}_{3}$ \\
\hline & 6199(b) & 0.01 & 16127 & 16132 & 2 & 97.5 & ${ }^{3} \mathrm{~F}_{2}$ & +1.22 & ${ }^{3} \mathrm{H}_{4}$ & +0.60 & ${ }^{3} \mathrm{~F}_{3}$ \\
\hline \multirow[t]{3}{*}{${ }^{1} \mathrm{G}_{4}$} & 4757.0 & 0.13 & $21016^{i}$ & 21017 & 2 & 99.5 & ${ }^{1} \mathrm{G}_{4}$ & +0.19 & ${ }^{3} \mathrm{H}_{4}$ & +0.12 & ${ }^{3} \mathrm{~F}_{3}$ \\
\hline & 4742.5 & 0.30 & $21081^{\mathrm{i}}$ & 21083 & 1 & 99.6 & ${ }^{1} \mathrm{G}_{4}$ & +0.12 & ${ }^{1} \mathrm{I}_{6}$ & +0.10 & ${ }^{3} \mathrm{~F}_{3}$ \\
\hline & 4735.4 & 0.02 & 21112 & & & & & & & & \\
\hline \multirow[t]{12}{*}{ (21 459) } & 4733.0 & 0.03 & 21122 & & & & & & & & \\
\hline & 4711.2 & 0.13 & $21221^{\mathrm{i}}$ & 21214 & 2 & 99.6 & ${ }^{1} \mathrm{G}_{4}$ & +0.13 & ${ }^{1} \mathrm{D}_{2}$ & +0.09 & ${ }^{1} I_{6}$ \\
\hline & 4709.0 & 0.18 & $21230^{\mathrm{i}}$ & 21231 & 1 & 99.5 & ${ }^{1} \mathrm{G}_{4}$ & +0.21 & ${ }^{1} \mathrm{D}_{2}$ & +0.08 & ${ }^{3} \mathrm{P}_{2}$ \\
\hline & 4703.2 & 0.03 & 21256 & & & & & & & & \\
\hline & 4699.2 & 0.02 & 21274 & & & & & & & & \\
\hline & 4664.4 & 0.10 & 21433 & & & & & & & & \\
\hline & 4656.8 & 0.38 & $21468^{\mathrm{i}}$ & 21472 & 1 & 99.5 & ${ }^{1} \mathrm{G}_{4}$ & +0.15 & ${ }^{1} I_{6}$ & +0.13 & ${ }^{1} \mathrm{D}_{2}$ \\
\hline & 4647.5 & 0.26 & 21511 & 21477 & 2 & 99.5 & ${ }^{1} \mathrm{G}_{4}$ & +0.15 & ${ }^{1} I_{6}$ & +0.15 & ${ }^{1} \mathrm{D}_{2}$ \\
\hline & 4639.0 & 0.02 & 21550 & & & & & & & & \\
\hline & & & & 21680 & 2 & 99.6 & ${ }^{1} \mathrm{G}_{4}$ & +0.14 & ${ }^{1} \mathrm{D}_{2}$ & +0.09 & ${ }^{3} \mathrm{H}_{5}$ \\
\hline & $4577(\mathrm{~b})$ & 0.01 & 21842 & 21827 & 1 & 99.6 & ${ }^{1} \mathrm{G}_{4}$ & +0.17 & ${ }^{3} \mathrm{~F}_{3}$ & +0.14 & ${ }^{3} \mathrm{H}_{4}$ \\
\hline & 4532(b) & 0.01 & 22060 & 22069 & 1 & 99.7 & ${ }^{1} \mathrm{G}_{4}$ & +0.08 & ${ }^{3} \mathrm{H}_{4}$ & +0.05 & ${ }^{3} \mathrm{P}_{2}$ \\
\hline $\begin{array}{l}{ }^{1} \mathrm{D}_{2} \\
(27607)\end{array}$ & 3657.9 & 0.44 & $27330^{\mathrm{i}}$ & 27330 & 1 & 99.7 & ${ }^{1} \mathrm{D}_{2}$ & +0.09 & ${ }^{3} \mathrm{~F}_{3}$ & +0.07 & ${ }^{1} \mathrm{G}_{4}$ \\
\hline
\end{tabular}

${ }^{a}$ Crystal contains 0.12 at. $\% \mathrm{Tm}\left(1.4 \times 10^{19} / \mathrm{cm}^{3}\right)$.

${ }^{\mathrm{b}}$ Multiplet manifolds of $\mathrm{Tm}^{3+}\left(4 f^{12}\right)$; calculated centroids are listed in parenthesis in $\mathrm{cm}^{-1}$.

${ }^{c}$ Wavelength (angstroms); b denotes broad; sh denotes shoulder.

${ }^{\mathrm{d}}$ Intensity of axial spectrum at $4 \mathrm{~K}$ in absorbance $/ \mathrm{cm}$.

${ }^{e}$ Energy level observed in absorption $\left(\mathrm{cm}^{-1}\right)$; levels also observed in fluorescence are marked with a star $(*)$.

${ }^{\mathrm{f}}$ Calculated energy level based on $\mathrm{Tm}^{3+}$ ions occupying $\mathrm{M}(\mathrm{II})$ sites having $C_{s}$ symmetry using crystal-field parameters $\left(B_{n m}\right)$ reported in Table VI.

${ }^{g}$ Predicted symmetry label $\left(\Gamma_{n}\right)$ of calculated Stark level.

${ }^{\mathrm{h}}$ Percent free-ion mixture of wave functions based on $C_{s}$ symmetry crystal-field parameters $\left(B_{n m}\right)$ reported in Table VI.

${ }^{\mathrm{i}}$ Energy levels used in final fitting analysis.

$\mathrm{Er}^{3+}$ in either SFAP or its analogue $\mathrm{Ca}_{5}\left(\mathrm{PO}_{4}\right)_{3} \mathrm{~F}$, known as FAP, have become better understood through analyses of site-selective excitation and emission spectroscopy. ${ }^{1,4,8-11}$ In Pr:SFAP ${ }^{4}$ as well as in Eu:SFAP, ${ }^{8}$ a single predominant site was determined spectroscopically; however, crystal-field splitting calculations did not yield satisfactory agreement with experimental Stark levels in either case. Similar calculations were more successful in analyzing the spectra of $\mathrm{Nd}^{3+}$ and $\mathrm{Er}^{3+}$ ions in Nd:SFAP, Nd:FAP, and Er:FAP. ${ }^{1,11}$ In the present study we chose $\mathrm{Tm}^{3+}$ as an optical probe in order to gain more specific information regarding the chargecompensated site occupied by the majority of $\mathrm{R}^{3+}$ ions in SFAP. ${ }^{12-19}$ The energy levels of $\mathrm{Tm}^{3+}$ are associated with a relatively simple electronic configuration $\left(4 f^{12}\right)$ with a sufficient number of multiplet manifolds, ${ }^{2 S+1} \mathrm{~L}_{\mathrm{J}}$, separated by a large spin-orbit splitting to permit a detailed analysis of the crystal-field splitting of the isolated manifolds.

In the present study we find that site-selective polarized emission spectra representing transitions from ${ }^{1} \mathrm{D}_{2},{ }^{1} \mathrm{G}_{4}$, and ${ }^{3} \mathrm{H}_{4}$ to manifolds ${ }^{3} \mathrm{H}_{6},{ }^{3} \mathrm{~F}_{4},{ }^{3} \mathrm{H}_{5},{ }^{3} \mathrm{H}_{4}$ and ${ }^{3} \mathrm{~F}_{3}$ of $\mathrm{Tm}^{3+}$ in Tm:SFAP are consistent with electric-dipole selection rules for $C_{s}$ symmetry. We find agreement between the observed Stark levels and the symmetry labels established for many of these levels obtained from an analysis of the polarized fluorescence data, and the calculated Stark levels and predicted symmetry labels based on a crystal-field splitting calculation in which the crystal-field Hamiltonian has $C_{s}$ symmetry. The starting set of crystal-field components, $A_{n m}$, were derived from a lattice-sum calculation in which the $\mathrm{F}^{-}$ion, which is nearest-neighbor ion to the $\mathrm{M}(\mathrm{II})$ site in which $\mathrm{Tm}^{3+}$ resides, is replaced by $\mathrm{O}^{2-}$ so that charge neutrality is maintained throughout the lattice. ${ }^{18}$ By varying the initial set of crystalfield parameters, $B_{n m}$, in order to optimize agreement between the calculated and observed Stark levels, we obtained a final rms value of $7 \mathrm{~cm}^{-1}$ between the energies of $43 \mathrm{cal}-$ culated and observed Stark levels. There is consistent agreement between the calculated and the experimentally assigned symmetry labels for these Stark levels as well.

From the final set of $B_{n m}$ parameters for $\mathrm{Tm}^{3+}$ we derived a starting set of parameters to be used in the crystalfield splitting analyses of the multiplet manifolds of $\operatorname{Er}^{3+}\left(4 f^{11}\right)$ ions in Er:SFAP. In $C_{s}$ symmetry all Stark levels of Kramers ions such as $\mathrm{Er}^{3+}$ (having an odd number of electrons in the electronic configuration) are twofold degenerate and have the same symmetry label, $\left({ }^{2} \Gamma_{6}\right)$. Both electric- and magnetic-dipole transitions are allowed between these Stark levels. ${ }^{1}$ With a small change in $B_{n m}$, parameters resulting from a least-squares fitting procedure, we obtained a rms difference of $8 \mathrm{~cm}^{-1}$ for 48 Stark levels of $\mathrm{Er}^{3+}$ in Er:SFAP assuming the $\mathrm{Er}^{3+}$ ions reside in sites of $C_{s}$ symmetry. The results of the present study support the earlier conclusion of Wright et al. ${ }^{4,8}$ that the majority of 


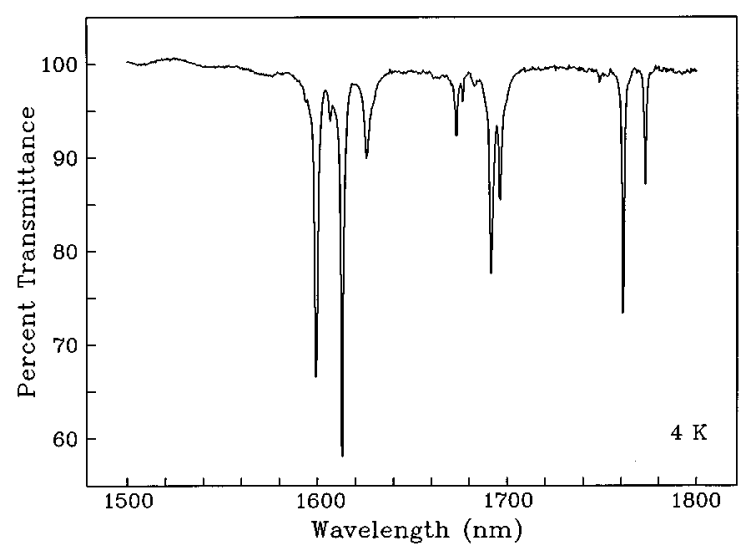

FIG. 1. Axial absorption spectrum of ${ }^{3} \mathrm{~F}_{4}, \mathrm{Tm}^{3+}$ in Tm:SFAP $(4 \mathrm{~K})$.

$\mathrm{R}^{3+}$ ions occupy sites of $C_{s}$ symmetry in the SFAP lattice and also support the assumption that in SFAP the nearest neighbor ( $\left.\mathrm{F}^{-}\right)$to the metal site $\mathrm{M}(\mathrm{II})$ having $C_{s}$ symmetry in the undoped crystal is replaced by divalent oxygen $\left(\mathrm{O}^{-}\right)$, thus preserving charge neutrality when the $\mathrm{R}^{3+}$ ion replaces the $\mathrm{Sr}^{2+}$ ion in the $\mathrm{M}(\mathrm{II})$ site.

\section{EXPERIMENTAL DETAILS}

Crystals of $\mathrm{Sr}_{5}\left(\mathrm{PO}_{4}\right)_{3} \mathrm{~F}$ containing either $\mathrm{Tm}^{3+}$ ions or $\mathrm{Er}^{3+}$ ions were grown by the Czochralski method at the University of Central Florida, Center for Research on Electrooptics and Lasers. ${ }^{7}$ The amount of rare earth in each sample used in our studies was determined by Galbraith Laboratories (Knoxville, TN), the results of which agree with determinations using inductively coupled plasma atomic emission spectrometry on chemically digested portions of the crystals. The data appearing in Tables I-III for $\mathrm{Tm}^{3+}$ in Tm:SFAP, and in Tables IV and $\mathrm{V}$ for $\mathrm{Er}^{3+}$ in Er:SFAP represent concentrations of 0.12 at. \% Tm and 0.15 at. \% Er, respectively.

Data appearing in Tables $\mathrm{I}-\mathrm{V}$ are based on single crystals having a hexagonal structure [space group $\left.\mathrm{P6}_{3} / \mathrm{m}\left(\mathrm{C}_{6 h}^{2}\right)\right]^{20}{ }^{20}$ There are two molecules per unit cell. ${ }^{21,22}$ In the undoped crystal $40 \%$ of the $\mathrm{Sr}^{2+}$ ions occupy the $\mathrm{M}(\mathrm{I})$ site ( $C_{3}$ symmetry), and the remaining $60 \%$ occupy the M(II)

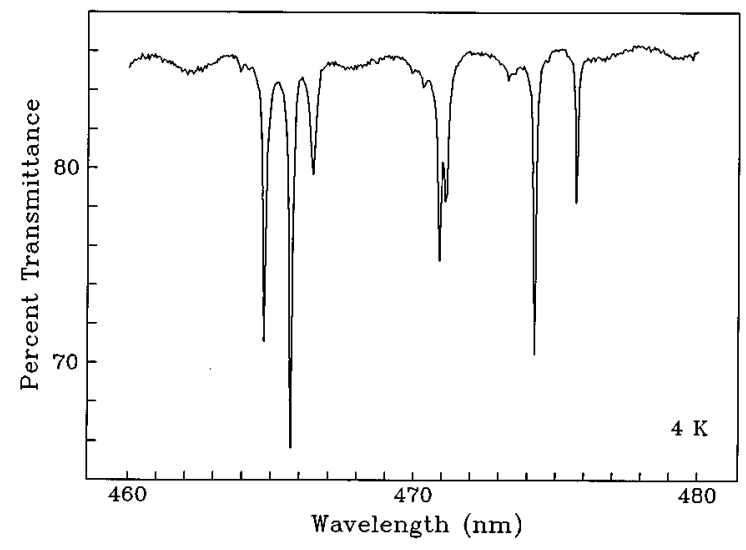

FIG. 2. Axial absorption spectrum of ${ }^{1} \mathrm{G}_{4}, \mathrm{Tm}^{3+}$ in Tm:SFAP $(4 \mathrm{~K})$. site $\left(C_{s}\right.$ symmetry). We observed no spectroscopic evidence to suggest a phase change in the crystals below room temperature. $^{23,24}$

The crystals were cut and polished parallel and perpendicular to the optical or $c$-axis. Axial and polarized transverse spectra ( $\sigma$ and $\pi$ polarizations) were obtained after the optical axis was determined by placing the crystal between crossed polarizers to observe the characteristic maltese cross pattern. ${ }^{8}$ Absorption spectra were obtained using a Cary model 2390 spectrophotometer equipped with a continuousflow liquid-helium cryostat (Oxford, Model 1204D) that allowed us to obtain spectra at any temperature between $4 \mathrm{~K}$ and room temperature. The instrument was calibrated by measuring deuterium emission lines in different orders. Supplemental absorption spectra were obtained at a temperature of approximately $35 \mathrm{~K}$ from a Perkin-Elmer Lambda 9 spectrophotometer equipped with a closed-cycle helium refrigerator.

Site-selective excitation and fluorescence spectra were obtained at $4 \mathrm{~K}$ using a Quantel Nd:YAG laser-pumped dye laser with an output bandwidth of about $0.1 \mathrm{~cm}^{-1}$. A $0.85 \mathrm{~m}$ double monochromator was used for fluorescence detection. Signals were processed using a boxcar averager and gated integrator. Data were collected and stored in a digital oscilloscope. Fluorescence lifetime measurements on $\mathrm{Tm}^{3+}$ samples were taken using a Continuum Nd:YAG Q-switched laser and relatively broad-band dye laser with Rhodamine dyes. We did not attempt to carry out site-selective lifetimes studies with this instrumentation. The frequency-tripled $\mathrm{Nd}$ :YAG output was used to excite ${ }^{1} \mathrm{D}_{2}$ whereas the dye laser output excited ${ }^{1} \mathrm{G}_{4}$ (via anti-Stokes Raman shifting in $\mathrm{H}_{2}$ gas) and ${ }^{3} \mathrm{H}_{4}$ (via Stokes Raman shifting). Detection was accomplished using a Spex monochromator, a Hamamatsu photomultiplier, and a Tektronix digitizing oscilloscope.

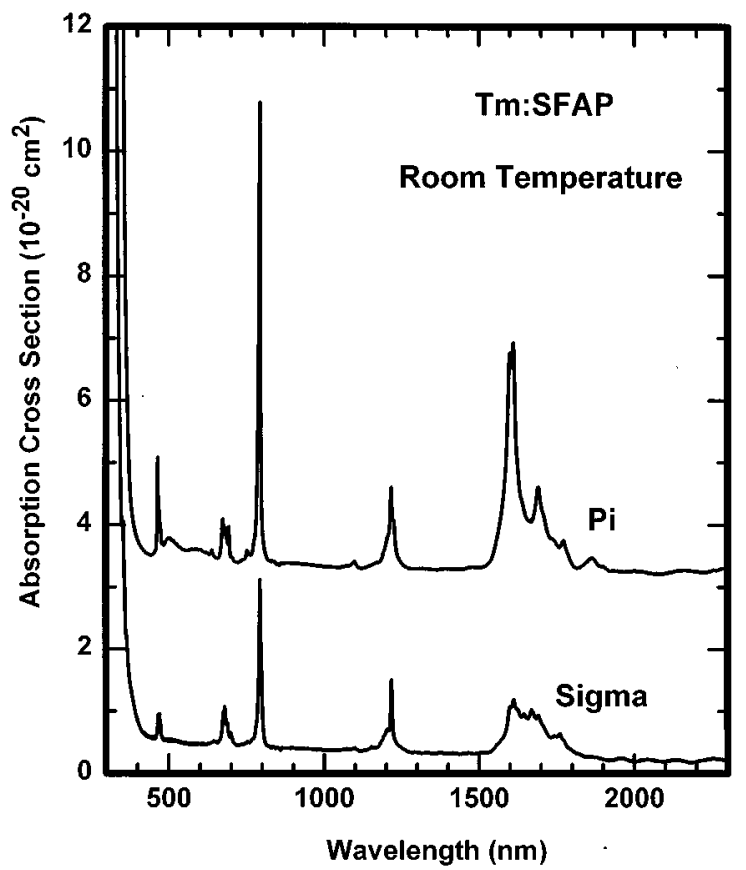

FIG. 3. Room temperature polarized absorption spectra of Tm:SFAP. 
TABLE II. Emission from ${ }^{1} \mathrm{G}_{4}$ to ${ }^{3} \mathrm{H}_{6},{ }^{3} \mathrm{~F}_{4}$, and ${ }^{3} \mathrm{H}_{5}: \mathrm{Tm}^{3+}$ in $\mathrm{Sr}_{5}\left(\mathrm{PO}_{4}\right)_{3} \mathrm{~F}$ at $4 \mathrm{~K} .{ }^{\mathrm{a}}$

\begin{tabular}{|c|c|c|c|c|c|c|c|c|c|}
\hline$\lambda(\AA)^{\mathrm{b}}$ & $I^{\mathrm{c}}$ & $P^{\mathrm{d}}$ & $E\left(\mathrm{~cm}^{-1}\right)^{\mathrm{e}}$ & $\begin{array}{c}\Delta E^{\mathrm{f}} \\
\left(\mathrm{cm}^{-1}\right)\end{array}$ & $\Gamma_{n}^{\mathrm{g}}$ & $\begin{array}{l}E\left(\mathrm{~cm}^{-1}\right)^{\mathrm{h}} \\
\quad(\text { obs. })\end{array}$ & $\begin{array}{c}E\left(\mathrm{~cm}^{-1}\right)^{\mathrm{i}} \\
\quad(\text { calc. })\end{array}$ & $\begin{array}{c}\Gamma_{n}{ }^{\mathrm{j}} \\
\text { (calc.) }\end{array}$ & ${ }^{2 S+1} \mathrm{~L}_{J}{ }^{\mathrm{k}}$ \\
\hline 4757.8 & vs & $\sigma$ & 21012 & 0 & 2 & 0 & 2 & 2 & \\
\hline 4758.8 & vs & $\pi$ & 21008 & 4 & 1 & 4 & 4 & 1 & \\
\hline 4773.8 & $\mathrm{~m}$ & $\sigma$ & 20942 & 70 & 2 & 70 & 68 & 2 & ${ }^{3} \mathrm{H}_{6}$ \\
\hline 4779(sh) & w & $\pi$ & 20919 & 93 & 1 & 90 & 86 & 1 & \\
\hline 4799.7 & $\mathrm{~m}$ & $\pi$ & 20829 & 183 & 1 & $175(b)$ & 174 & 1 & $(549)$ \\
\hline 4796.3 & $\mathrm{~m}$ & $\sigma$ & 20844 & 168 & 2 & & 190 & 2 & \\
\hline 4822(b) & $\mathrm{m}$ & $\pi$ & 20732 & & & & & & \\
\hline \multirow[t]{3}{*}{4842.5} & vw & $\pi$ & 20645 & & & & & & \\
\hline & & & & & & & 504 & 2 & \\
\hline & & & & & & & 511 & 1 & \\
\hline \multirow[t]{4}{*}{4923.5} & $\mathrm{~m}$ & $\pi$ & 20305 & $707^{1}$ & 1 & & 673 & 1 & \\
\hline & & & & & & & 881 & 2 & \\
\hline & & & & & & & 950 & 2 & \\
\hline & & & & & & & 1300 & 1 & \\
\hline 5078.1 & w & $\pi$ & 19687 & 1325 & 1 & & 1319 & 1 & \\
\hline 6502.2 & $\mathrm{~s}$ & $\sigma$ & 15375 & 5637 & 2 & 5639 & 5646 & 2 & \\
\hline \multirow[t]{2}{*}{6518.1} & vs & $\pi$ & 15338 & 5674 & 1 & 5678 & 5719 & 1 & ${ }^{3} \mathrm{~F}_{4}$ \\
\hline & & & & & & 5717 & & & \\
\hline \multirow{2}{*}{$\begin{array}{l}6618.8 \\
6620(\mathrm{sh})\end{array}$} & $\mathrm{m}$ & $\pi$ & 15104 & 5908 & 1 & 5910 & 5909 & 1 & $(6000)$ \\
\hline & $\mathrm{m}$ & & 15100 & 5912 & & 5914 & 5918 & 2 & \\
\hline 6642.2 & $\mathrm{~s}$ & $\pi$ & 15051 & 5961 & 1 & 5963 & 5970 & 1 & \\
\hline 6647.4 & $\mathrm{~m}$ & $\sigma$ & 15039 & 5973 & 2 & 5975 & 5976 & 2 & \\
\hline 6725.4 & $\mathrm{~m}$ & $\pi$ & 14865 & 6147 & 1 & 6150 & 6137 & 1 & \\
\hline 6747.9 & $\mathrm{~m}$ & $\sigma$ & 14815 & 6197 & 2 & 6199 & 6205 & 2 & \\
\hline 6771.6 & w & $\pi$ & 14763 & 6249 & 1 & 6252 & 6245 & 1 & \\
\hline 7808.5 & vs & $\sigma$ & 12803 & 8209 & 2 & 8211 & 8207 & 2 & \\
\hline 7808 (sh) & $\mathrm{s}$ & $\pi$ & 12800 & 8212 & 1 & 8213 & 8215 & 1 & \\
\hline $7866(\mathrm{vb})$ & $\mathrm{m}$ & $\pi$ & 12709 & 8303 & 1 & $8301(\mathrm{vb})$ & 8303 & 1 & ${ }^{3} \mathrm{H}_{5}$ \\
\hline $7871(\mathrm{vb})$ & $\mathrm{m}$ & $\pi$ & 12701 & $8311^{l}$ & 1 & & & & \\
\hline 7895.4 & w & $\sigma$ & 12662 & 8350 & 2 & 8352 & 8352 & 2 & (8647) \\
\hline 7934(b) & $\mathrm{m}$ & & 12604 & 8408 & & 8410 & 8405 & 2 & \\
\hline 7948.8 & $\mathrm{~s}$ & $\pi$ & 12577 & 8435 & 1 & 8436 & 8441 & 1 & \\
\hline \multirow[t]{5}{*}{8137.3} & $\mathrm{~s}$ & & 12286 & 8726 & & 8730 & 8731 & 2 & \\
\hline & & & & & & $8870(\mathrm{~b})$ & 8868 & 1 & \\
\hline & & & & & & $8950(\mathrm{~b})$ & 8945 & 1 & \\
\hline & & & & & & & 9321 & 2 & \\
\hline & & & & & & $9330(b)$ & 9339 & 2 & \\
\hline
\end{tabular}

${ }^{\mathrm{a} C}$ Crystal contains 0.12 at. $\% \mathrm{Tm}\left(1.4 \times 10^{19} / \mathrm{cm}^{3}\right)$.

${ }^{\mathrm{b}}$ Emission observed from lowest Stark level of ${ }^{1} \mathrm{G}_{4}$ identified in absorption (Table I) at 4757.0 A; sh (shoulder), b (broad), vb (very broad).

${ }^{\mathrm{c}}$ Relative intensity (axial spectrum) within a multiplet manifold, vs (very strong), s (strong), m (medium), w (weak), vw (very weak).

${ }^{\mathrm{d}}$ Polarization of the transverse emission spectra $(4 \mathrm{~K})$.

energy of the transition in $\mathrm{cm}^{-1}$.

${ }^{\mathrm{f}}$ Energy difference based on emitting level at $21012 \mathrm{~cm}^{-1}$.

${ }^{\mathrm{g}}$ Assigned symmetry label on the assumption of $C_{s}$ symmetry selection rules for $\mathrm{Tm}^{3+}$ ions occupying $\mathrm{M}(\mathrm{II})$ sites.

${ }^{\text {h}}$ Stark levels 70,90 , and $175 \mathrm{~cm}^{-1}$ are based on analysis of absorption hot bands; other levels were identified from absorption spectra obtained $\sim 4 \mathrm{~K}$.

${ }^{\mathrm{i}}$ Calculated splitting based on crystal-field parameters $\left(B_{n m}\right)$ reported in Table VI.

${ }^{\mathrm{j} S y m m e t r y ~ l a b e l ~ o f ~ c a l c u l a t e d ~ S t a r k ~ l e v e l ~ o b t a i n e d ~ u s i n g ~} B_{n m}$ parameters reported in Table VI.

${ }^{\mathrm{k}}$ Multiplet manifold of $\mathrm{Tm}^{3+}\left(4 f^{12}\right)$; number in parenthesis is the calculated centroid.

${ }^{\mathrm{l}}$ Levels not included in the final fitting analysis.

Temperature dependent data were acquired using a CTI closed cycle refrigerator system.

Room temperature fluorescence lifetime measurements on $\mathrm{Er}^{3+}$ samples were taken using a temperature-tuned, pulsed, Spectra Diode Labs InGaAs laser diode array with the fluorescence being detected with a Germanium Power
Devices Ge photodiode. Wavelength selection was accomplished with colored glass filters.

\section{THE OBSERVED SPECTRA OF Tm:SFAP}

We report the axial absorption spectrum of Tm:SFAP (4 $\mathrm{K}$ ) in Table I (column 2) between 1780 and $345 \mathrm{~nm}$. This 
TABLE III. Emission from ${ }^{1} \mathrm{D}_{2}$ to ${ }^{3} \mathrm{H}_{6},{ }^{3} \mathrm{~F}_{4},{ }^{3} \mathrm{H}_{5}$, and ${ }^{3} \mathrm{~F}_{3}: \mathrm{Tm}^{3+}$ in $\mathrm{Sr}_{5}\left(\mathrm{PO}_{4}\right)_{3} \mathrm{~F}$ at $4 \mathrm{~K}$.

\begin{tabular}{|c|c|c|c|c|c|c|c|c|c|}
\hline$\lambda(\AA)^{b}$ & $I^{\mathrm{c}}$ & $P^{\mathrm{d}}$ & $E\left(\mathrm{~cm}^{-1}\right)^{\mathrm{e}}$ & $\begin{array}{c}\Delta E^{\mathrm{f}} \\
\left(\mathrm{cm}^{-1}\right)\end{array}$ & $\Gamma_{n}^{\mathrm{g}}$ & $\begin{array}{l}E\left(\mathrm{~cm}^{-1}\right)^{\mathrm{h}} \\
\quad(\text { obs. })\end{array}$ & $\begin{array}{c}E\left(\mathrm{~cm}^{-1}\right)^{\mathrm{i}} \\
\quad(\text { calc. })\end{array}$ & $\begin{array}{c}\Gamma_{n}{ }^{\mathrm{j}} \\
\text { (calc.) }\end{array}$ & ${ }^{2 S+1} \mathrm{~L}_{J}{ }^{\mathrm{k}}$ \\
\hline 3648.8 & vw & & 27398 & & & & & & \\
\hline 3658.4 & vs & $\pi$ & 27327 & 0 & 2 & 0 & 2 & 2 & ${ }^{3} \mathrm{H}_{6}$ \\
\hline 3659 (sh) & $\mathrm{m}$ & $\sigma$ & 27322 & 4 & 1 & 4 & 4 & 1 & $(549)$ \\
\hline 3667.8 & $\mathrm{w}$ & & 27257 & 70 & & 70 & 68 & 2 & \\
\hline $3670(\mathrm{sh})$ & w & $\sigma$ & 27237 & 90 & 1 & 90 & 86 & 1 & \\
\hline 3680.4 & vs & $\pi$ & 27163 & 164 & 2 & $175(b)$ & 174 & 1 & \\
\hline 3683.2 & $\mathrm{~s}$ & $\sigma$ & 27143 & 184 & 1 & & 190 & 2 & \\
\hline 3695.3(b) & w & $\sigma$ & 27054 & $273^{1}$ & & & & & \\
\hline \multirow[t]{3}{*}{ 3697.6(b) } & $\mathrm{w}$ & $\pi$ & 27037 & $290^{1}$ & & & & & \\
\hline & & & & & & & 504 & 2 & \\
\hline & & & & & & & 511 & 1 & \\
\hline \multirow[t]{3}{*}{$3755(b)$} & vw & & 26624 & $705^{\mathrm{j}}$ & & & 673 & 1 & \\
\hline & & & & & & & 881 & 2 & \\
\hline & & & & & & & 950 & 2 & \\
\hline $3842(\mathrm{sh})$ & $\mathrm{m}$ & $\sigma$ & 26021 & $1306^{1}$ & 1 & & 1300 & 1 & \\
\hline 3844.8 & vs & $\sigma$ & 26002 & 1325 & 1 & & 1319 & 1 & \\
\hline 4602.6 & vw & $\pi$ & 21721 & & & & & & \\
\hline 4610.0 & vs & $\pi$ & 21686 & 5641 & 2 & 5639 & 5646 & 2 & ${ }^{3} \mathrm{~F}_{4}$ \\
\hline 4617.8 & vs & & 21649 & 5678 & & 5677 & 5719 & 1 & \\
\hline 4653.7 & vw & & 21482 & & & & & & $(6000)$ \\
\hline 4664.6 & $\mathrm{~m}$ & & 21432 & & & & & & \\
\hline 4667.9 & vs & $\sigma$ & 21417 & 5910 & 1 & 5910 & 5909 & 1 & \\
\hline 4680.0 & $\mathrm{~m}$ & $\sigma$ & 21362 & 5965 & 1 & 5963 & 5970 & 1 & \\
\hline 4682.2 & $\mathrm{~m}$ & $\pi$ & 21352 & 5975 & 2 & 5975 & 5976 & 2 & \\
\hline 4689(sh) & vw & & 21321 & & & & & & \\
\hline 4721.0 & $\mathrm{~m}$ & & 21176 & 6151 & & 6150 & 6137 & 1 & \\
\hline 4732.2 & $\mathrm{~m}$ & $\pi$ & 21126 & 6201 & 2 & 6199 & 6205 & 2 & \\
\hline 4744.0 & vw & & 21073 & 6254 & & 6252 & 6245 & 1 & \\
\hline $5231(\mathrm{sh})$ & $\mathrm{m}$ & $\pi$ & 19114 & 8213 & 2 & 8211 & 8207 & 2 & ${ }^{3} \mathrm{H}_{5}$ \\
\hline 5229.4 & $\mathrm{~s}$ & $\sigma$ & 19117 & 8210 & 1 & 8213 & 8215 & 1 & \\
\hline $5255(\mathrm{~b})$ & $\mathrm{m}$ & $\sigma$ & 19024 & 8303 & 1 & 8301 & 8303 & 1 & $(8647)$ \\
\hline $5261(\mathrm{sh})$ & vw & & 19001 & & & & & & \\
\hline 5269.6 & $\mathrm{~s}$ & $\pi$ & 18974 & 8353 & 2 & 8352 & 8352 & 2 & \\
\hline $5272(\mathrm{sh})$ & vw & & 18961 & & & & & & \\
\hline $5284(\mathrm{~b})$ & $\mathrm{s}$ & $\pi$ & 18920 & 8407 & 2 & 8410 & 8405 & 2 & \\
\hline 5294.7 & $\mathrm{~s}$ & & 18882 & $8445^{1}$ & & 8436 & 8441 & 1 & \\
\hline 5332(b) & $\mathrm{w}$ & & 18749 & $8578^{1}$ & & 8581 & & & \\
\hline 5375(b) & $\mathrm{m}$ & $\pi$ & 18599 & 8728 & 2 & 8730 & 8731 & 2 & \\
\hline \multirow[t]{5}{*}{$5390(b)$} & vw & & 18548 & & & & & & \\
\hline & & & & & & 8870 & 8868 & 1 & \\
\hline & & & & & & 8950 & 8945 & 1 & \\
\hline & & & & & & 9330 & 9321 & 2 & \\
\hline & & & & & & & 9339 & 2 & \\
\hline 6761.9 & vw & & 14785 & & & & & & \\
\hline 6780.9 & $\mathrm{~s}$ & $\pi$ & 14743 & 12584 & 2 & 12586 & 12586 & 2 & ${ }^{3} \mathrm{H}_{4}$ \\
\hline 6785.2 & vs & $\sigma$ & 14734 & 12593 & 1 & 12595 & 12595 & 1 & \\
\hline 6803.0 & vs & $\sigma$ & 14695 & 12632 & 1 & 12633 & 12635 & 1 & (12 910) \\
\hline \multirow[t]{3}{*}{6827.7} & $\mathrm{~m}$ & $\pi$ & 14642 & 12685 & 2 & 12686 & 12681 & 2 & \\
\hline & & & & & & 12723 & 12726 & 1 & \\
\hline & & & & & & $12740^{1}$ & 12740 & 2 & \\
\hline 6880.8 & $\mathrm{~m}$ & $\pi$ & 14529 & 12798 & & $12802(\mathrm{vw})$ & & & \\
\hline $6891(\mathrm{vb})$ & w & $\pi$ & 14491 & 12836 & & & & & \\
\hline \multirow[t]{4}{*}{6925.5} & $\mathrm{~m}$ & $\pi$ & 14435 & 12892 & & $12893^{1}$ & & & \\
\hline & & & & & & $13236^{1}$ & 13230 & 2 & \\
\hline & & & & & & $13285^{1}$ & 13266 & 1 & \\
\hline & & & & & & 13296 & 13320 & 1 & \\
\hline 7713.0 & $\mathrm{~m}$ & $\pi$ & 12962 & & & & & & \\
\hline 7736.7 & $\mathrm{~s}$ & $\pi$ & 12922 & 14405 & 2 & 14407 & 14397 & 2 & ${ }^{3} \mathrm{~F}_{3}$ \\
\hline 7902.4 & $\mathrm{~s}$ & $\sigma$ & 12651 & 14676 & 1 & 14677 & 14668 & 1 & \\
\hline \multirow[t]{2}{*}{7908.1} & $\mathrm{~s}$ & & 12642 & 14685 & & 14688 & 14693 & 2 & (14 675) \\
\hline & & & & & & 14769 & 14775 & 1 & \\
\hline 7981.8 & $\mathrm{~m}$ & $\pi$ & 12525 & 14802 & 2 & 14804 & 14816 & 2 & \\
\hline 8014.0 & $\mathrm{~m}$ & $\sigma$ & 12475 & 14852 & 1 & 14852 & 14859 & 1 & \\
\hline 8033.3 & vs & $\pi$ & 12445 & 14882 & 2 & 14883 & 14879 & 2 & \\
\hline
\end{tabular}

${ }^{\mathrm{a}}$ Crystal contains 0.12 at. $\% \mathrm{Tm}\left(1.4 \times 10^{19} / \mathrm{cm}^{3}\right)$.

${ }^{b}$ Emission observed from lowest Stark level of ${ }^{1} \mathrm{D}_{2}$ identified in absorption (Table I) at $3657.9 \AA ̊$; sh (shoulder), b (broad), vb (very broad).

${ }^{\mathrm{c}}$ Relative intensity (axial spectrum) within a multiplet manifold, vs (very strong), s (strong), m (medium), w (weak), vw (very weak).

${ }^{\mathrm{d}}$ Polarization of the transverse emission spectra $(4 \mathrm{~K})$.

${ }^{\mathrm{e}}$ Energy of the transition in $\mathrm{cm}^{-1}$.

${ }^{\mathrm{f}}$ Energy difference based on emitting level at $27327 \mathrm{~cm}^{-1}$.

${ }^{\mathrm{g}}$ Assigned symmetry label based on the assumption of $C_{s}$ symmetry selection rules for $\mathrm{Tm}^{3+}$ ions occupying M(II) sites.

${ }^{\mathrm{h}}$ Stark levels 70,90 , and $175 \mathrm{~cm}^{-1}$ based on analysis of absorption hot bands; other levels based on analysis of $4 \mathrm{~K}$ absorption spectrum.

${ }^{\mathrm{i}}$ Calculated splitting based on $B_{n m}$ parameters reported in Table VI.

${ }^{j}$ Symmetry label of calculated Stark level obtained using $B_{n m}$ parameters in Table VI.

${ }^{\mathrm{k}}$ Multiplet manifold of $\mathrm{Tm}^{3+}\left(4 f^{12}\right)$; number in parenthesis is the calculated centroid.

${ }^{\mathrm{l}}$ Levels not included in the final fitting analysis. 
wavelength range includes the spectra of transitions to multiplet manifolds of $\mathrm{Tm}^{3+}\left(4 f^{12}\right)$ including ${ }^{3} \mathrm{~F}_{4},{ }^{3} \mathrm{H}_{5},{ }^{3} \mathrm{H}_{4}$, ${ }^{3} \mathrm{~F}_{3},{ }^{1} \mathrm{G}_{4}$, and ${ }^{1} \mathrm{D}_{2}$. At wavelengths shorter than $310 \mathrm{~nm}$ the crystal itself begins to absorb, making it impossible to observe spectra of the ${ }^{1} \mathrm{I}_{6}$ and ${ }^{3} \mathrm{P}_{\mathrm{J}}$ manifolds. Only the lowest energy (emitting Stark level) of the ${ }^{1} \mathrm{D}_{2}$ manifold is reported since the onset of the absorption by the crystal also includes spectra possibly due to defects and centers attributed to the charge-compensation required to preserve charge neutrality in the lattice. ${ }^{11}$

The absorption spectrum of each manifold usually consists of $2 J+1$ relatively strong peaks along with weaker and usually broader peaks which are attributed to $\mathrm{Tm}^{3+}$ ions in minority sites. Representative spectra obtained at $4 \mathrm{~K}$ are given in Fig. $1\left({ }^{3} \mathrm{~F}_{4}\right)$ and Fig. $2\left({ }^{1} \mathrm{G}_{4}\right)$. A survey of the polarized absorption spectra of Tm:SFAP obtained at room temperature is given in Fig. 3. At room temperature the spectra are observed in both $\sigma$ and $\pi$ polarizations. At temperatures approaching $4 \mathrm{~K}$ the sharpest peaks have sufficient resolution to indicate that transitions occur from the groundstate Stark level and the first excited-state Stark level separated by only $4 \mathrm{~cm}^{-1}$. The polarization of the $4 \mathrm{~K}$ absorption spectra of the sharpest peaks indicates that the ground-state Stark level and the $4 \mathrm{~cm}^{-1}$ excited state Stark level have different symmetries. The clearest evidence for these observations is found among the spectra of the ${ }^{3} \mathrm{~F}_{3}$ multiplet manifold, although to varying degrees of resolution, the $4 \mathrm{~K}$ spectra of other multiplet manifolds show similar evidence for the $4 \mathrm{~cm}^{-1}$ splitting. In Fig. 4 for example the 4 and $10 \mathrm{~K}$ polarized absorption spectra are given for the emitting Stark level in ${ }^{1} \mathrm{G}_{4}(475.7 \mathrm{~nm}$, Table I). The growth of hot bands observed at $10 \mathrm{~K}$ provides evidence for the $4 \mathrm{~cm}^{-1}$ splitting. However, we relied on site-selective excitation to produce polarized fluorescence to help us resolve the dilemma.

Polarized fluorescence spectra obtained by site-selective excitation were observed from the ${ }^{1} \mathrm{D}_{2}(366 \mathrm{~nm}),{ }^{1} \mathrm{G}_{4}$ (476 $\mathrm{nm})$, and ${ }^{3} \mathrm{H}_{4}(794 \mathrm{~nm})$ levels to the ground-state manifold, ${ }^{3} \mathrm{H}_{6}$. The spectra clearly indicate that the ground-state Stark level and the first excited Stark level have different symmetry and are separated by $4 \mathrm{~cm}^{-1}$. Table II presents the polarized fluorescence spectra from ${ }^{1} \mathrm{G}_{4}$ to ${ }^{3} \mathrm{H}_{6},{ }^{3} \mathrm{~F}_{4}$, and ${ }^{3} \mathrm{H}_{5}$, multiplet manifolds. Table III reports the polarized fluorescence spectra observed from ${ }^{1} \mathrm{D}_{2}$ to ${ }^{3} \mathrm{H}_{6},{ }^{3} \mathrm{~F}_{4},{ }^{3} \mathrm{H}_{5},{ }^{3} \mathrm{H}_{4}$, and ${ }^{3} \mathrm{~F}_{3}$. The data in both tables were obtained at $4 \mathrm{~K}$. The strongest $2 J+1$ absorption peaks for manifolds also observed in fluorescence can be matched to Stark levels whose energy and symmetry are determined from an analysis of the polarized fluorescence appearing in Tables II and III. Figure 5 is a composite figure showing the sigma, pi, unpolarized transverse, and the axial spectra for transitions from ${ }^{1} \mathrm{G}_{4}$ to ${ }^{3} \mathrm{H}_{6}$. A similar composite represents fluorescence from ${ }^{1} \mathrm{G}_{4}$ to ${ }^{3} \mathrm{~F}_{4}$ (Fig. 6), ${ }^{1} \mathrm{G}_{4}$ to ${ }^{3} \mathrm{H}_{5}$ (Fig. 7), and ${ }^{1} \mathrm{D}_{2}$ to ${ }^{3} \mathrm{~F}_{4}$ (Fig. 8).

The polarized fluorescence spectra can be interpreted by assuming that the $\mathrm{Tm}^{3+}$ ions occupy sites of $C_{s}$ symmetry. In such symmetry Stark levels are labeled either $\Gamma_{1}$ or $\Gamma_{2} .{ }^{25}$ In the transverse spectrum both electric- and magneticdipole transitions have the same selection rules. ${ }^{26}$

\begin{tabular}{ccc}
$C_{s}$ & $\Gamma_{1}$ & $\Gamma_{2}$ \\
\hline$\Gamma_{1}$ & $\sigma$ & $\pi$ \\
$\Gamma_{2}$ & $\pi$ & $\sigma$
\end{tabular}

Transitions appearing in both the transverse $\sigma$-polarized spectrum and the axial spectrum are electric-dipole in character and represent the only type of transition observed.

The polarizations reported in Tables II and III suggest that the emitting Stark levels from ${ }^{1} \mathrm{G}_{4}$ and ${ }^{1} \mathrm{D}_{2}$ have different symmetries since the terminal levels are the same. If we choose $\Gamma_{1}$, for the emitting ${ }^{1} \mathrm{G}_{4}$ level (Table II, $21012 \mathrm{~cm}^{-1}$ ) and $\Gamma_{2}$ symmetry for the emitting ${ }^{1} \mathrm{D}_{2}$ level (Table III, $27327 \mathrm{~cm}^{-1}$ ) based on the predicted symmetries obtained from calculations described in the next section, we find complete consistency both in energy and symmetry label for the most intense fluorescence peaks appearing in both tables. Symmetry label assignments $\left(\Gamma_{1}\right.$ or $\left.\Gamma_{2}\right)$ have been made to all Stark levels where polarized transitions to that level are unambiguous. Since these assignments can be applied to nearly all the spectra reported in Tables II and III we conclude that the majority of $\mathrm{Tm}^{3+}$ ions occupy a site having $C_{s}$ symmetry.

\section{FLUORESCENCE LIFETIME MEASUREMENTS ON Tm:SFAP}

Fluorescence lifetime measurements can be useful in learning more regarding the interaction between the $\mathrm{Tm}^{3+}$ ions and the host lattice, SFAP. Decay waveforms have been measured for emission from multiplet manifolds ${ }^{1} \mathrm{G}_{4},{ }^{1} \mathrm{D}_{2}$, and ${ }^{3} \mathrm{H}_{4}$ to the ground-state manifold, ${ }^{3} \mathrm{H}_{6}$. Figure 9 shows the room temperature fluorescence decay waveforms for ${ }^{1} \mathrm{G}_{4}$ and ${ }^{3} \mathrm{H}_{4}$. The ${ }^{1} \mathrm{G}_{4}$ emission exhibits a nearly exponential decay with only a very weak faster initial decay. This observation supports the assumption that the spectra are dominated by $\mathrm{Tm}^{3+}$ ions in a single type of site. The fact that the decay lifetime shows relatively little temperature dependence, changing from about $340 \mu \mathrm{s}$ at $16 \mathrm{~K}$ to about $310 \mu \mathrm{s}$ at room temperature, suggests that the lifetime may be predominantly radiative. This lifetime is somewhat shorter than the comparable emission observed for $\mathrm{Tm}^{3+}$ ions in some other host crystals such as $\mathrm{Y}_{2} \mathrm{SiO}_{5},{ }^{27}$ but is consistent with the strong transitions evident in the Tm:SFAP absorption data (see Fig. 3). The room temperature emission from the ${ }^{1} \mathrm{D}_{2}$ to the ${ }^{3} \mathrm{H}_{6}$ manifold exhibits a single exponential decay with a lifetime of $9.1 \mu \mathrm{s}$.

However, the ${ }^{3} \mathrm{H}_{4}$ room temperature emission monitored at $795 \mathrm{~nm}$ following excitation at $788 \mathrm{~nm}$, exhibits very different behavior. This decay, also shown in Fig. 9, is well approximated by the sum of two exponentials, with lifetimes of 3.0 and $37 \mu$ s. These results indicate that emitting $\mathrm{Tm}^{3+}$ ions occupy at least two different environments. The brevity of these lifetimes, compared to the ${ }^{3} \mathrm{H}_{4}$ lifetime in other hosts, suggests that nonradiative processes are important at least for the faster decay. ${ }^{27-29}$ About two-thirds of the integrated intensity is in the faster decay, despite the likelihood that strong quenching gives it a low probability per ion of fluorescing. There is evidence of minority site absorption to ${ }^{3} \mathrm{H}_{4}$, particularly in the shoulders of the intense absorption peaks at 7943.2 and $7937.5 \AA$ (Table I). However, time resolved spectroscopy did not reveal distinct fluorescence 
TABLE IV. Absorption spectrum of $\mathrm{Er}^{3+}$ in $\mathrm{Sr}_{5}\left(\mathrm{PO}_{4}\right)_{3} \mathrm{~F}$ at $4 \mathrm{~K} .^{\mathrm{a}}$

\begin{tabular}{|c|c|c|c|c|c|c|c|c|c|c|}
\hline \multirow{2}{*}{$\frac{{ }^{2 S+1} \mathrm{~L}_{J}{ }^{\mathrm{b}}}{{ }^{4} \mathrm{I}_{13 / 2}}$} & \multirow{2}{*}{$\frac{\lambda(\AA)^{\mathrm{c}}}{15336}$} & \multirow{2}{*}{$\frac{\alpha^{\mathrm{d}}}{0.01}$} & \multirow{2}{*}{$\frac{E\left(\mathrm{~cm}^{-1}\right)_{\mathrm{obs}}^{\mathrm{e}}}{6519}$} & \multirow[t]{2}{*}{$E\left(\mathrm{~cm}^{-1}\right)_{\text {calc }}^{\mathrm{f}}$} & \multicolumn{6}{|c|}{ Percent free-ion mixture ${ }^{\mathrm{g}}$} \\
\hline & & & & & & & & & & \\
\hline & 15306 & 0.73 & $6532^{\mathrm{h}, \mathrm{i}}$ & 6542 & 99.8 & ${ }^{4} I_{13 / 2}$ & +0.06 & ${ }^{4} \mathrm{I}_{11 / 2}$ & +0.04 & ${ }^{4} \mathrm{G}_{9 / 2}$ \\
\hline \multirow[t]{9}{*}{$(6715)$} & 15172 & 0.22 & $6589^{\mathrm{h}, \mathrm{i}}$ & 6583 & 99.8 & ${ }^{4} \mathrm{I}_{13 / 2}$ & +0.09 & ${ }^{4} \mathrm{I}_{11 / 2}$ & +0.04 & ${ }^{4} \mathrm{I}_{15 / 2}$ \\
\hline & 15 163(sh) & 0.15 & 6592 & & & & & & & \\
\hline & 15124 & 0.51 & $6610^{\mathrm{h}, \mathrm{i}}$ & 6615 & 99.8 & ${ }^{4} \mathrm{I}_{13 / 2}$ & +0.09 & ${ }^{4} \mathrm{I}_{11 / 2}$ & +0.06 & ${ }^{4} \mathrm{I}_{15 / 2}$ \\
\hline & 15 095(b) & 0.02 & 6624 & & & & & & & \\
\hline & 15052 & 0.15 & $6643^{\mathrm{h}, \mathrm{i}}$ & 6635 & 99.8 & ${ }^{4} \mathrm{I}_{13 / 2}$ & ${ }^{+} 0.09$ & ${ }^{4} \mathrm{I}_{11 / 2}$ & +0.04 & ${ }^{4} \mathrm{I}_{15 / 2}$ \\
\hline & 15 020(b) & 0.01 & 6656 & & & & & & & \\
\hline & $14940(b)$ & 0.05 & $6690^{\mathrm{i}}$ & 6690 & 99.7 & ${ }^{4} I_{13 / 2}$ & +0.22 & ${ }^{4} \mathrm{I}_{11 / 2}$ & +0.04 & ${ }^{4} \mathrm{I}_{15 / 2}$ \\
\hline & $14680(b)$ & 0.02 & $6810^{\mathrm{i}}$ & 6807 & 99.5 & ${ }^{4} \mathrm{I}_{13 / 2}$ & +0.34 & ${ }^{4} \mathrm{I}_{11 / 2}$ & +0.06 & ${ }^{4} \mathrm{I}_{15 / 2}$ \\
\hline & 14210 & 0.12 & $7035^{\mathrm{h}, \mathrm{i}}$ & 7036 & 99.8 & ${ }^{4} \mathrm{I}_{13 / 2}$ & +0.13 & ${ }^{4} \mathrm{I}_{11 / 2}$ & +0.04 & ${ }^{4} \mathrm{I}_{15 / 2}$ \\
\hline \multirow[t]{2}{*}{${ }^{4} \mathrm{I}_{11 / 2}$} & 9815.0 & 0.01 & 10186 & & & & & & & \\
\hline & 9797.2 & 0.17 & $10204^{\mathrm{h}, \mathrm{i}}$ & 10203 & 99.7 & ${ }^{4} I_{11 / 2}$ & +0.13 & ${ }^{4} \mathrm{I}_{13 / 2}$ & +0.08 & ${ }^{4} \mathrm{I}_{9 / 2}$ \\
\hline \multirow[t]{6}{*}{ (10 304) } & 9771.1 & 0.06 & $10225^{\mathrm{i}}$ & 10219 & 99.6 & ${ }^{4} \mathrm{I}_{11 / 2}$ & +0.15 & ${ }^{4} \mathrm{I}_{9 / 2}$ & +0.10 & ${ }^{4} \mathrm{I}_{13 / 2}$ \\
\hline & 9765.0 & 0.04 & $10238^{i}$ & 10244 & 99.7 & ${ }^{4} \mathrm{I}_{11 / 2}$ & +0.09 & ${ }^{4} \mathrm{I}_{13 / 2}$ & +0.07 & ${ }^{4} \mathrm{~F}_{9 / 2}$ \\
\hline & 9750.1 & 0.03 & $10253^{\mathrm{i}}$ & 10255 & 99.6 & ${ }^{4} I_{11 / 2}$ & +0.17 & ${ }^{4} \mathrm{~F}_{9 / 2}$ & +0.17 & ${ }^{4} I_{13 / 2}$ \\
\hline & 9704(b) & 0.01 & 10302 & & & & & & & \\
\hline & $9659(b)$ & 0.01 & $10350^{\mathrm{i}}$ & 10349 & 99.5 & ${ }^{4} I_{11 / 2}$ & +0.27 & ${ }^{4} I_{13 / 2}$ & +0.15 & ${ }^{4} \mathrm{~F}_{9 / 2}$ \\
\hline & $9540(b)$ & 0.04 & 10480 & 10503 & 99.5 & ${ }^{4} \mathrm{I}_{11 / 2}$ & +0.26 & ${ }^{4} \mathrm{I}_{13 / 2}$ & +0.10 & ${ }^{4} \mathrm{I}_{9 / 2}$ \\
\hline \multirow[t]{2}{*}{${ }^{4} \mathrm{I}_{9 / 2}$} & 8087.0 & 0.08 & $12362^{\mathrm{h}, \mathrm{i}}$ & 12373 & 99.7 & ${ }^{4} \mathrm{I}_{9 / 2}$ & +0.10 & ${ }^{2} \mathrm{H}_{11 / 2}$ & +0.10 & ${ }^{4} \mathrm{~F}_{9 / 2}$ \\
\hline & 8014.0 & 0.02 & $12475^{\mathrm{i}}$ & 12469 & 99.3 & ${ }^{4} \mathrm{I}_{9 / 2}$ & +0.30 & ${ }^{4} \mathrm{~F}_{9 / 2}$ & +0.18 & ${ }^{4} \mathrm{I}_{11 / 2}$ \\
\hline \multirow[t]{3}{*}{ (12 549) } & 7977.5 & 0.16 & $12533^{\mathrm{i}}$ & 12529 & 99.5 & ${ }^{4} \mathrm{I}_{9 / 2}$ & +0.27 & ${ }^{4} \mathrm{~F}_{9 / 2}$ & +0.09 & ${ }^{4} \mathrm{I}_{11 / 2}$ \\
\hline & 7948.0 & 0.09 & $12578^{\mathrm{i}}$ & 12580 & 99.5 & ${ }^{4} I_{9 / 2}$ & +0.14 & ${ }^{4} \mathrm{~F}_{9 / 2}$ & +0.10 & ${ }^{4} \mathrm{I}_{11 / 2}$ \\
\hline & 7863(b) & 0.02 & $12714^{\mathrm{i}}$ & 12710 & 99.2 & ${ }^{4} \mathrm{I}_{9 / 2}$ & +0.58 & ${ }^{4} \mathrm{~F}_{9 / 2}$ & +0.09 & ${ }^{2} \mathrm{H}_{11 / 2}$ \\
\hline \multirow[t]{2}{*}{${ }^{4} \mathrm{~F}_{9 / 2}$} & 6619.5 & 0.25 & $15103^{\mathrm{h}, \mathrm{i}}$ & 15120 & 98.3 & ${ }^{4} \mathrm{~F}_{9 / 2}$ & +0.86 & ${ }^{4} \mathrm{I}_{9 / 2}$ & +0.46 & ${ }^{2} \mathrm{H}_{11 / 2}$ \\
\hline & 6614.5 & 0.01 & 15114 & & & & & & & \\
\hline \multirow[t]{8}{*}{ (15 304) } & 6611.1 & 0.01 & 15122 & & & & & & & \\
\hline & 6601.0 & 0.44 & $15145^{\mathrm{h}, \mathrm{i}}$ & 15140 & 99.1 & ${ }^{4} \mathrm{~F}_{9 / 2}$ & +0.48 & ${ }^{2} \mathrm{H}_{11 / 2}$ & +0.16 & ${ }^{4} \mathrm{I}_{9 / 2}$ \\
\hline & 6594.6 & 0.02 & 15160 & & & & & & & \\
\hline & 6566(b) & 0.16 & 15226 & & & & & & & \\
\hline & 6564(sh) & 0.10 & 15230 & & & & & & & \\
\hline & 6540(b) & 0.03 & 15286 & 15285 & 99.3 & ${ }^{4} \mathrm{~F}_{9 / 2}$ & +0.32 & ${ }^{2} \mathrm{H}_{11 / 2}$ & +0.11 & ${ }^{4} \mathrm{I}_{9 / 2}$ \\
\hline & 6481.2 & 0.21 & $15425^{\mathrm{h}, \mathrm{i}}$ & 15412 & 99.5 & ${ }^{4} \mathrm{~F}_{9 / 2}$ & +0.15 & ${ }^{4} \mathrm{I}_{9 / 2}$ & +0.13 & ${ }^{2} \mathrm{H}_{11 / 2}$ \\
\hline & 6427.5 & 0.27 & $15552^{\mathrm{h}}$ & 15517 & 99.6 & ${ }^{4} F_{9 / 2}$ & +0.17 & ${ }^{4} \mathrm{I}_{9 / 2}$ & +0.08 & ${ }^{4} \mathrm{I}_{11 / 2}$ \\
\hline \multirow[t]{2}{*}{${ }^{4} S_{3 / 2}$} & 5492.1 & 0.19 & $18203^{\mathrm{h}, \mathrm{i}}$ & 18208 & 97.6 & ${ }^{4} \mathrm{~S}_{3 / 2}$ & +2.12 & ${ }^{2} \mathrm{H}_{11 / 2}$ & +0.07 & ${ }^{4} \mathrm{I}_{9 / 2}$ \\
\hline & 5487.2 & 0.02 & 18219 & & & & & & & \\
\hline \multirow[t]{3}{*}{ (18 346) } & 5477.0 & 0.02 & 18253 & & & & & & & \\
\hline & 5429.2 & 0.08 & $18414^{\mathrm{h}, \mathrm{i}}$ & 18408 & 94.0 & ${ }^{4} \mathrm{~S}_{3 / 2}$ & +5.69 & ${ }^{2} \mathrm{H}_{11 / 2}$ & +0.09 & ${ }^{4} \mathrm{~F}_{7 / 2}$ \\
\hline & 5420.4 & 0.01 & 18444 & & & & & & & \\
\hline${ }^{2} \mathrm{H}_{11 / 2}$ & 5281.0 & 0.02 & 18931 & & & & & & & \\
\hline & 5272.9 & 1.19 & $18960^{\mathrm{h}}$ & 19043 & 98.3 & ${ }^{2} \mathrm{H}_{11 / 2}$ & +0.73 & ${ }^{4} \mathrm{~F}_{7 / 2}$ & +0.67 & ${ }^{4} \mathrm{~S}_{3 / 2}$ \\
\hline (19 149) & 5267.4 & 0.04 & 18979 & & & & & & & \\
\hline & 5232.3 & 0.02 & 19107 & & & & & & & \\
\hline & 5231.1 & 0.02 & $19111^{\mathrm{i}}$ & 19105 & 98.4 & ${ }^{2} \mathrm{H}_{11 / 2}$ & +0.76 & ${ }^{4} S_{3 / 2}$ & +0.58 & ${ }^{4} \mathrm{~F}_{7 / 2}$ \\
\hline & 5226.2 & 0.03 & 19129 & & & & & & & \\
\hline & 5221.8 & 3.33 & $19145^{\mathrm{h}, \mathrm{i}}$ & 19136 & 96.8 & ${ }^{2} \mathrm{H}_{11 / 2}$ & +1.62 & ${ }^{4} \mathrm{~F}_{7 / 2}$ & +1.26 & ${ }^{4} \mathrm{~S}_{3 / 2}$ \\
\hline & 5215.7 & 2.09 & $19168^{\mathrm{h}, \mathrm{i}}$ & 19174 & 94.6 & ${ }^{2} \mathrm{H}_{11 / 2}$ & +3.97 & ${ }^{4} \mathrm{~S}_{3 / 2}$ & +0.88 & ${ }^{4} \mathrm{~F}_{7 / 2}$ \\
\hline & $5213.6(\mathrm{sh})$ & 0.20 & 19175 & & & & & & & \\
\hline & 5210.9 & 0.04 & 19188 & & & & & & & \\
\hline & 5202(sh) & 1.30 & 19218 & & & & & & & \\
\hline & 5199.8 & 3.25 & $19226^{\mathrm{h}, \mathrm{i}}$ & 19234 & 97.6 & ${ }^{2} \mathrm{H}_{11 / 2}$ & +0.96 & ${ }^{4} \mathrm{~F}_{7 / 2}$ & +0.59 & ${ }^{4} S_{3 / 2}$ \\
\hline & 5191.8 & 3.30 & $19256^{\mathrm{h}, \mathrm{i}}$ & 19252 & 97.5 & ${ }^{2} \mathrm{H}_{11 / 2}$ & +1.16 & ${ }^{4} \mathrm{~F}_{7 / 2}$ & +0.64 & ${ }^{4} \mathrm{~S}_{3 / 2}$ \\
\hline & 5189(sh) & 0.40 & 19266 & & & & & & & \\
\hline & 5183.0 & 0.05 & 19288 & & & & & & & \\
\hline${ }^{4} F_{7 / 2}$ & 4951.0 & 0.01 & 20192 & & & & & & & \\
\hline & 4948.8 & 0.04 & 20201 & & & & & & & \\
\hline$(20505)$ & 4945.4 & 0.83 & $20215^{\mathrm{h}, \mathrm{i}}$ & 20213 & 97.6 & ${ }^{4} \mathrm{~F}_{7 / 2}$ & +1.47 & ${ }^{2} \mathrm{H}_{11 / 2}$ & +0.36 & ${ }^{4} \mathrm{G}_{9 / 2}$ \\
\hline
\end{tabular}




\begin{tabular}{|c|c|c|c|c|c|c|c|c|c|c|}
\hline \multirow[t]{2}{*}{${ }^{2 S+1} \mathrm{~L}_{J}^{\mathrm{b}}$} & \multirow{2}{*}{$\frac{\lambda(\AA)^{c}}{4941(b)}$} & \multirow{2}{*}{$\frac{\alpha^{\mathrm{d}}}{0.03}$} & \multirow{2}{*}{$\frac{E\left(\mathrm{~cm}^{-1}\right)_{\mathrm{obs}}^{\mathrm{e}}}{20233}$} & \multirow[t]{2}{*}{$E\left(\mathrm{~cm}^{-1}\right)_{\text {calc }}{ }^{\mathrm{f}}$} & \multicolumn{6}{|c|}{ Percent free-ion mixture ${ }^{\mathrm{g}}$} \\
\hline & & & & & & & & & & \\
\hline & 4936.2 & 0.01 & 20253 & & & & & & & \\
\hline & 4878.0 & 0.17 & $20494^{\mathrm{h}, \mathrm{i}}$ & 20490 & 96.4 & ${ }^{4} \mathrm{~F}_{7 / 2}$ & +2.13 & ${ }^{2} \mathrm{H}_{11 / 2}$ & +0.66 & ${ }^{4} \mathrm{~F}_{5 / 2}$ \\
\hline & 4875.2 & 0.02 & 20506 & & & & & & & \\
\hline & 4855.5 & 0.13 & $20589^{\mathrm{h}, \mathrm{i}}$ & 20589 & 96.4 & ${ }^{4} \mathrm{~F}_{7 / 2}$ & +1.51 & ${ }^{4} \mathrm{~F}_{5 / 2}$ & +1.50 & ${ }^{2} \mathrm{H}_{11 / 2}$ \\
\hline & 4854(sh) & 0.03 & 20596 & & & & & & & \\
\hline & 4838.3 & 0.49 & $20663^{\mathrm{h}, \mathrm{i}}$ & 20667 & 97.8 & ${ }^{4} \mathrm{~F}_{7 / 2}$ & +1.04 & ${ }^{2} \mathrm{H}_{11 / 2}$ & +0.66 & ${ }^{4} \mathrm{~F}_{5 / 2}$ \\
\hline & 4836(sh) & 0.07 & 20672 & & & & & & & \\
\hline \multirow[t]{2}{*}{${ }^{4} \mathrm{~F}_{5 / 2}$} & 4537.6 & 0.17 & $22032^{\mathrm{h}, \mathrm{i}}$ & 22013 & 97.7 & ${ }^{4} \mathrm{~F}_{5 / 2}$ & +0.91 & ${ }^{4} \mathrm{~F}_{7 / 2}$ & +0.53 & ${ }^{4} \mathrm{~F}_{3 / 2}$ \\
\hline & 4536(sh) & 0.03 & 22040 & & & & & & & \\
\hline \multirow[t]{4}{*}{ (22 112) } & 4533.1 & 0.01 & 22054 & & & & & & & \\
\hline & 4532.2 & 0.07 & $22058^{\mathrm{i}}$ & 22053 & 73.7 & ${ }^{4} \mathrm{~F}_{5 / 2}$ & +24.2 & ${ }^{4} \mathrm{~F}_{3 / 2}$ & +1.23 & ${ }^{4} \mathrm{~F}_{7 / 2}$ \\
\hline & 4522.0 & 0.12 & $22108^{\mathrm{h}, \mathrm{i}}$ & 22130 & 92.2 & ${ }^{4} \mathrm{~F}_{5 / 2}$ & +6.52 & ${ }^{4} \mathrm{~F}_{3 / 2}$ & +0.89 & ${ }^{4} \mathrm{~F}_{7 / 2}$ \\
\hline & $4520(\mathrm{sh})$ & 0.02 & 22118 & & & & & & & \\
\hline \multirow{2}{*}{${ }^{4} \mathrm{~F}_{3 / 2}$} & 4453(b) & 0.01 & 22452 & & & & & & & \\
\hline & 4450.0 & 0.02 & $22466^{\mathrm{i}}$ & 22475 & 75.1 & ${ }^{4} \mathrm{~F}_{3 / 2}$ & +24.1 & ${ }^{4} \mathrm{~F}_{5 / 2}$ & +0.58 & ${ }^{4} \mathrm{~F}_{7 / 2}$ \\
\hline \multirow[t]{2}{*}{$(22529)$} & 4399(sh) & 0.02 & 22726 & & & & & & & \\
\hline & 4398.2 & 0.07 & $22730^{\mathrm{h}, \mathrm{i}}$ & 22725 & 92.4 & ${ }^{4} F_{3 / 2}$ & +7.18 & ${ }^{4} \mathrm{~F}_{5 / 2}$ & +0.16 & ${ }^{4} \mathrm{~F}_{7 / 2}$ \\
\hline \multirow{2}{*}{${ }^{2} \mathrm{G}_{9 / 2}$} & 4108.2 & 0.29 & $24335^{\mathrm{h}, \mathrm{i}}$ & 24332 & 97.9 & ${ }^{2} \mathrm{G}_{9 / 2}$ & +1.42 & ${ }^{4} \mathrm{G}_{11 / 2}$ & +0.35 & ${ }^{2} \mathrm{~K}_{15 / 2}$ \\
\hline & 4104.3 & 0.02 & 24358 & & & & & & & \\
\hline \multirow[t]{7}{*}{ (24 509) } & 4100.3 & 0.30 & $24382^{\mathrm{h}, \mathrm{i}}$ & 24384 & 96.9 & ${ }^{2} \mathrm{G}_{9 / 2}$ & +2.41 & ${ }^{4} \mathrm{G}_{11 / 2}$ & +0.37 & ${ }^{2} \mathrm{~K}_{15 / 2}$ \\
\hline & 4096.5 & 0.02 & 24404 & & & & & & & \\
\hline & 4085.0 & 0.02 & 24473 & 24490 & 98.5 & ${ }^{2} \mathrm{G}_{9 / 2}$ & +0.79 & ${ }^{4} \mathrm{G}_{11 / 2}$ & +0.36 & ${ }^{2} \mathrm{~K}_{15 / 2}$ \\
\hline & 4072.1 & 0.23 & 24551 & 24565 & 99.0 & ${ }^{2} \mathrm{G}_{9 / 2}$ & +0.33 & ${ }^{4} \mathrm{G}_{11 / 2}$ & +0.30 & ${ }^{2} \mathrm{~K}_{15 / 2}$ \\
\hline & 4062.3 & 0.24 & 24610 & & & & & & & \\
\hline & 4056.3 & 0.16 & $24646^{\mathrm{h}, \mathrm{i}}$ & 24649 & 98.8 & ${ }^{2} \mathrm{G}_{9 / 2}$ & +0.48 & ${ }^{2} \mathrm{~K}_{15 / 2}$ & +0.48 & ${ }^{4} \mathrm{G}_{11 / 2}$ \\
\hline & 4055.1 & 0.02 & 24653 & & & & & & & \\
\hline \multirow[t]{2}{*}{${ }^{4} \mathrm{G}_{11 / 2}$} & 3849.2 & 1.29 & $25972^{\mathrm{h}}$ & 26128 & 98.1 & ${ }^{4} \mathrm{G}_{11 / 2}$ & +0.85 & ${ }^{2} \mathrm{~K}_{15 / 2}$ & +0.82 & ${ }^{4} \mathrm{G}_{9 / 2}$ \\
\hline & 3843.6 & 0.06 & 26010 & & & & & & & \\
\hline \multirow[t]{14}{*}{$(26305)$} & 3812.7 & 0.03 & 26221 & 26196 & 98.2 & ${ }^{4} \mathrm{G}_{11 / 2}$ & +0.87 & ${ }^{4} G_{9 / 2}$ & +0.65 & ${ }^{2} \mathrm{~K}_{15 / 2}$ \\
\hline & 3810.9 & 0.02 & 26233 & & & & & & & \\
\hline & 3803.7 & 1.92 & $26289^{\mathrm{h}, \mathrm{i}}$ & 26295 & 96.3 & ${ }^{4} \mathrm{G}_{11 / 2}$ & +1.72 & ${ }^{2} \mathrm{~K}_{15 / 2}$ & +1.56 & ${ }^{4} \mathrm{G}_{9 / 2}$ \\
\hline & 3802(sh) & 0.15 & 26294 & & & & & & & \\
\hline & 3797.4 & 2.25 & $26326^{\mathrm{h}, \mathrm{i}}$ & 26324 & 94.0 & ${ }^{4} \mathrm{G}_{11 / 2}$ & +2.70 & ${ }^{4} G_{9 / 2}$ & +1.98 & ${ }^{2} \mathrm{~K}_{15 / 2}$ \\
\hline & 3795(sh) & 0.18 & 26343 & & & & & & & \\
\hline & 3792.3 & 0.10 & 26362 & & & & & & & \\
\hline & 3786.8 & 1.20 & 26400 & & & & & & & \\
\hline & 3783.2 & 3.60 & $26426^{\mathrm{i}}$ & 26429 & 93.5 & ${ }^{4} \mathrm{G}_{11 / 2}$ & +2.45 & ${ }^{2} \mathrm{~K}_{15 / 2}$ & +1.89 & ${ }^{4} \mathrm{G}_{9 / 2}$ \\
\hline & 3781.0 & 2.14 & 26441 & & & & & & & \\
\hline & 3777.0 & 3.60 & $26468^{\mathrm{i}}$ & 26461 & 94.3 & ${ }^{4} \mathrm{G}_{11 / 2}$ & +1.93 & ${ }^{2} \mathrm{~K}_{15 / 2}$ & +1.66 & ${ }^{4} \mathrm{G}_{5 / 2}$ \\
\hline & 3774(sh) & 1.90 & 26490 & & & & & & & \\
\hline & 3770.3 & 0.08 & 26516 & & & & & & & \\
\hline & 3765.0 & 0.04 & 26553 & & & & & & & \\
\hline
\end{tabular}

${ }^{a}$ Crystal contains 0.15 at. $\% \mathrm{Er},\left(1.7 \times 10^{19} / \mathrm{cm}^{3}\right)$.

${ }^{\mathrm{b}}$ Multiplet manifolds of $\mathrm{Er}^{3+}\left(4 f^{11}\right)$; calculated centroids are listed in parenthesis in $\mathrm{cm}^{-1}$.

${ }^{\mathrm{c}}$ Wavelength (angstroms); sh denotes shoulder; b denotes broad.

${ }^{\mathrm{d} I n t e n s i t y ~ o f ~ a x i a l ~ s p e c t r u m ~}(4 \mathrm{~K})$ in absorbance/cm.

${ }^{\text {e}}$ Energy of observed levels in $\mathrm{cm}^{-1}$.

${ }^{\mathrm{f}}$ Calculated energy levels for $\mathrm{Er}^{3+}$ ions occupying a charge-compensated $\mathrm{Sr}^{2+}\left(\mathrm{M}_{2}\right)$ site having $C_{s}$ symmetry; crystal-field parameters are given in Table VI. ${ }^{g}$ Percent free-ion mixture of wave functions based on the $C_{s}$ symmetry crystal-field parameters $\left(B_{\mathrm{nm}}\right)$ reported in Table VI.

${ }^{\text {h}} \mathrm{Hot}$ bands found in absorption to this level at $70,133,165$, and $260 \mathrm{~cm}^{-1}$; levels within the ground-state manifold, ${ }^{4} \mathrm{I}_{15 / 2}$, corresponding to these hot bands have an uncertainty of $\pm 3 \mathrm{~cm}^{-1}$ due to the breadth and shape of the hot bands.

${ }^{\mathrm{i}}$ Levels used in fitting analysis.

spectra with different decay times. It is not clear whether the different decay rates correspond to spectroscopically distinct sites.

The rapid decay of ${ }^{3} \mathrm{H}_{4}$ may be due to intraionic or interionic effects. The former is possible because unusually large phonon energies are available in the phosphate apatites, and the energy separation between ${ }^{3} \mathrm{H}_{4}$ and ${ }^{3} \mathrm{H}_{5}$ is smaller than that between ${ }^{1} \mathrm{G}_{4}$ and ${ }^{3} \mathrm{~F}_{2}$, or that between ${ }^{1} \mathrm{D}_{2}$ and ${ }^{1} \mathrm{G}_{4}$. Despite the relatively low thulium concentration in the crystal, cross-relaxation may also be important, given the strong electronic transitions observed in Table I and Fig. 3 and the near resonance evident for the process 
TABLE V. Emission from ${ }^{4} \mathrm{~S}_{3 / 2}$ to ${ }^{4} \mathrm{I}_{15 / 2}$ at $4 \mathrm{~K}$ (Er:SFAP). ${ }^{\mathrm{a}}$

\begin{tabular}{lccccc}
\hline \hline$\lambda(\AA)^{\mathrm{b}}$ & $E\left(\mathrm{~cm}^{-1}\right)^{\mathrm{c}}$ & $I^{\mathrm{d}}$ & Trans. $^{\mathrm{e}}$ & $\Delta E\left(\mathrm{~cm}^{-1}\right)^{\mathrm{f}}$ & $E\left(\mathrm{~cm}^{-1}\right)_{\text {calc }}{ }^{\mathrm{g}}$ \\
\hline 5477.5 & 18251 & $\mathrm{vw}$ & & & \\
5492.7 & 18201 & $\mathrm{~s}$ & $\mathrm{~B}_{1} \rightarrow \mathrm{Z}_{1}$ & 0 & -7 \\
5502.1 & 18170 & $\mathrm{vw}$ & & & \\
5513.9 & 18131 & $\mathrm{vs}$ & $\mathrm{B}_{1} \rightarrow \mathrm{Z}_{2}$ & $70^{\mathrm{h}}$ & 65 \\
$5529.5(\mathrm{sh})$ & 18080 & $\mathrm{~m}$ & & & \\
5533.2 & 18068 & $\mathrm{vs}$ & $\mathrm{B}_{1} \rightarrow \mathrm{Z}_{3}$ & $133^{\mathrm{h}}$ & 136 \\
5542.9 & 18036 & $\mathrm{~m}$ & $\mathrm{~B}_{1} \rightarrow \mathrm{Z}_{4}$ & $165^{\mathrm{h}}$ & 173 \\
5556.1 & 17993 & $\mathrm{~m}$ & & & \\
5572.2 & 17941 & $\mathrm{~m}$ & $\mathrm{~B}_{1} \rightarrow \mathrm{Z}_{5}$ & $260^{\mathrm{h}}$ & 260 \\
$5600(\mathrm{~b})$ & 17853 & $\mathrm{w}$ & & $348^{\mathrm{i}}$ & 359 \\
5638 & 17731 & $\mathrm{vw}$ & & $470^{\mathrm{i}}$ & 478 \\
5688.2 & 17575 & $\mathrm{vw}$ & & & 694 \\
5709.9 & 17509 & $\mathrm{vs}$ & $\mathrm{B}_{1} \rightarrow \mathrm{Z}_{8}$ & 692 & 694 \\
\hline \hline
\end{tabular}

${ }^{a}$ Excitation at $520 \mathrm{~nm}\left({ }^{2} \mathrm{H}_{11 / 2}\right.$ multiplet manifold).

${ }^{\mathrm{b}}$ Fluorescence measured in angstroms.

${ }^{c}$ Energy in vacuum wavenumbers.

${ }^{\mathrm{d}}$ Relative intensity (see Fig. 11); vw (very weak); w (weak); m (medium); s (strong); vs (very strong).

${ }^{\mathrm{e}}$ Transition from lowest energy Stark level of ${ }^{4} \mathrm{~S}_{3 / 2}$ corresponding to $18203 \mathrm{~cm}^{-1}$ in absorption (see Table III), to Stark levels of ${ }^{4} \mathrm{I}_{15 / 2}\left(\mathrm{Z}_{n}\right)$. ${ }^{\mathrm{f}}$ Difference in energy $\left(\mathrm{cm}^{-1}\right)$ using $B_{1}=18201 \mathrm{~cm}^{-1}$.

${ }^{\mathrm{g}}$ Calculated splitting of the ${ }^{4} \mathrm{I}_{15 / 2}$ multiplet manifold using crystal-field parameters $\left(B_{n m}\right)$ given in Table VI.

${ }^{\mathrm{h}}$ Stark levels identified in absorption from hot bands are listed as $\mathrm{Z}_{1}=0$, $\mathrm{Z}_{2}=70, \mathrm{Z}_{3}=133, \mathrm{Z}_{4}=165$, and $\mathrm{Z}_{5}=260 \mathrm{~cm}^{-1}$.

${ }^{\mathrm{i}}$ Levels not used in fitting analysis.

$\left({ }^{3} \mathrm{H}_{6}\right.$ lowest state, ${ }^{3} \mathrm{H}_{4}$ lowest state $) \rightarrow\left({ }^{3} \mathrm{~F}_{4}\right.$ highest state, ${ }^{3} \mathrm{~F}_{4}$ highest state).

Room temperature fluorescence branching ratios for ${ }^{1} \mathrm{G}_{4}$, Tm:SFAP, have been reported by Merkle, Zandi, and Chai. ${ }^{29}$ For convenience we include their results here as follows $\left({ }^{3} \mathrm{H}_{6}, 0.80\right),\left({ }^{3} \mathrm{~F}_{4}, 0.10\right),\left({ }^{3} \mathrm{H}_{5}, 0.05\right),\left({ }^{3} \mathrm{H}_{4}, 0.05\right)$, and $\left({ }^{3} \mathrm{~F}_{3},{ }^{3} \mathrm{~F}_{2},<0.1\right)$. We do not have branching ratios for other fluorescing manifolds.

\section{CALCULATED CRYSTAL-FIELD SPLITTING FOR Tm:SFAP}

The initial $B_{\mathrm{nm}}$ parameters used in the crystal-field splitting calculations were derived from a lattice-sum calculation
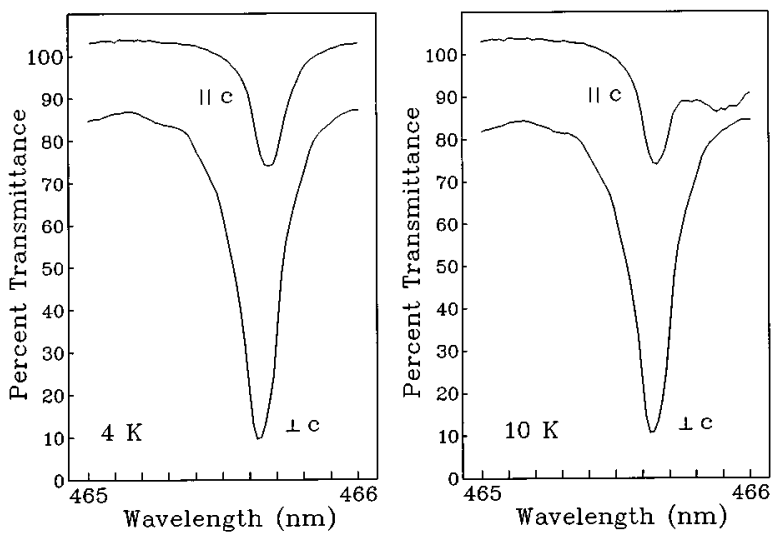

FIG. 4. Transverse absorption spectra of emitting level in ${ }^{1} \mathrm{G}_{4}(4757 \AA$, Table $\mathrm{I}$ at $4 \mathrm{~K}$ and $10 \mathrm{~K}$ showing the growth of a hot band that represents a transition from a Stark level $4 \mathrm{~cm}^{-1}$ above the ground-state Stark level. in which trivalent thulium substitutes for divalent strontium in the $\mathrm{M}(\mathrm{II})$ site $\left(C_{s}\right.$ symmetry). The nearest-neighbor fluoride $\left(\mathrm{F}^{-}\right)$is assumed to be replaced by divalent oxygen $\left(\mathrm{O}^{2-}\right)$ thus preserving overall charge neutrality and local symmetry. ${ }^{18}$

The total Hamiltonian for $\mathrm{Tm}^{3+}$ includes the free-ion coulombic and spin-orbit terms for all $\mathrm{SLJM}_{\mathrm{J}}$ states of the $4 f^{12}$ electronic configuration and the crystal electric field terms reflecting $C_{s}$ symmetry. The Racah and spin-orbit parameters entering into the free-ion part were obtained from an analysis of the aqueous solution spectra. ${ }^{30}$ The crystalfield Hamiltonian is of the form

$$
H_{\mathrm{CEF}}=\sum_{n \text { even }} \times \sum_{m=-n}^{n} B_{n m}^{*} \sum_{i=1}^{12} C_{n m}(i)
$$

where the $B_{n m}$ are the crystal-field parameters, and the $C_{n m}$ are expressed as

$$
C_{n m}(i)=\left[\frac{4 \pi}{(2 n+1)}\right]^{1 / 2} Y_{n m}\left(\theta_{i}, \rho_{i}\right)
$$

with

$$
C_{n-m}=(-1)^{m} C_{n m}^{*} .
$$

The $Y_{n m}$ are spherical harmonics. In $C_{s}$ symmetry values of $m$ are restricted by $n+m=0, \pm 2, \pm 4$, with $|m| \leqslant n$ and $n$ $=2,4,6$. The $n$-even $B_{n m}$ parameters are restricted to 15 in $C_{s}$ symmetry, but with a simple rotation about the principal

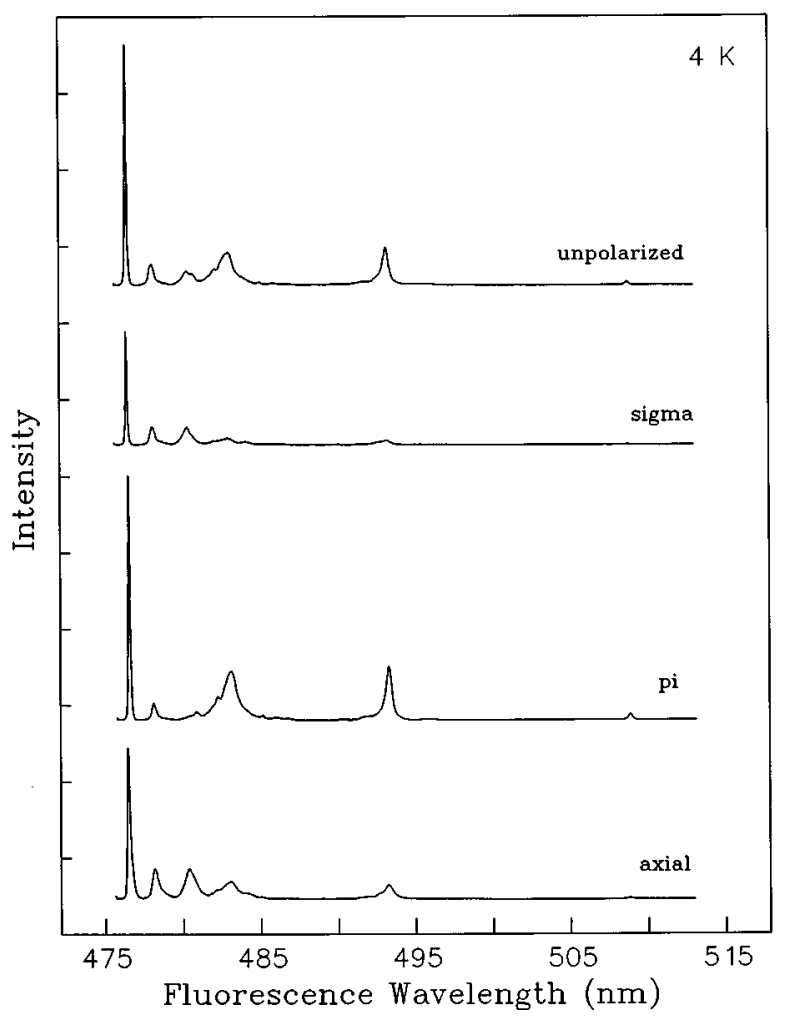

FIG. 5. Polarized emission spectra (transverse and axial) from the ${ }^{1} \mathrm{G}_{4}$ to the ${ }^{3} \mathrm{H}_{6}$ multiplet manifold at $4 \mathrm{~K}$. 


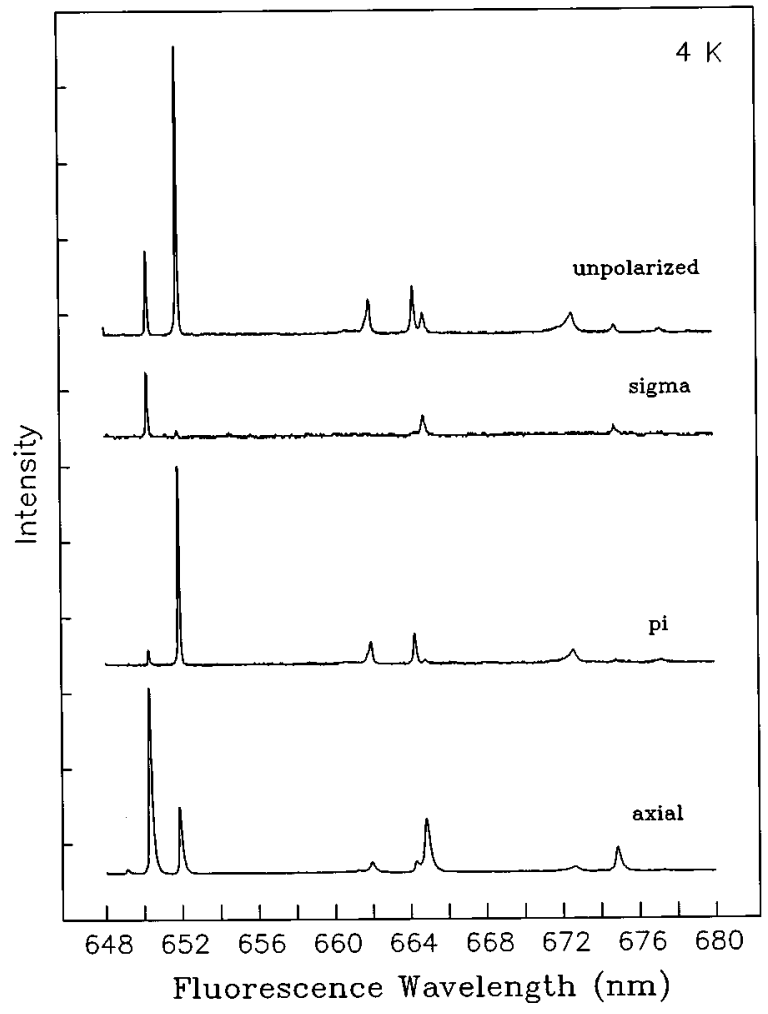

FIG. 6. Polarized emission spectra (transverse and axial) from the ${ }^{1} \mathrm{G}_{4}$ to the ${ }^{3} \mathrm{~F}_{4}$ multiplet manifold at $4 \mathrm{~K}$.

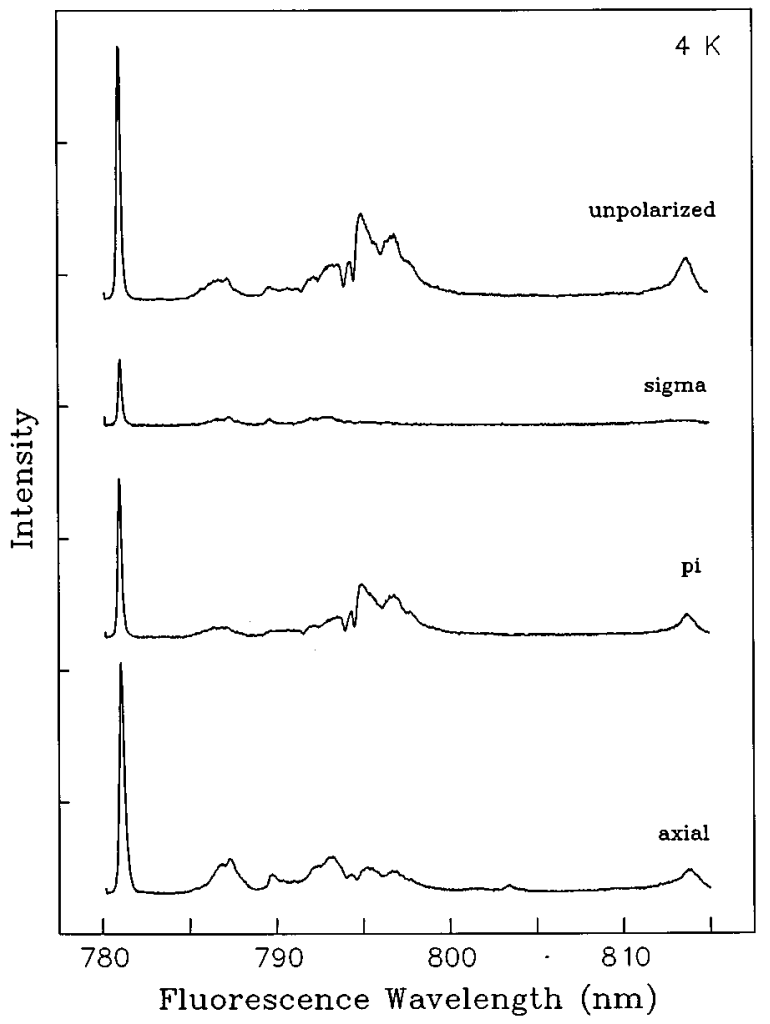

FIG. 7. Polarized emission spectra (transverse and axial) from the ${ }^{1} \mathrm{G}_{4}$ to the ${ }^{3} \mathrm{H}_{5}$ multiplet manifold at $4 \mathrm{~K}$.

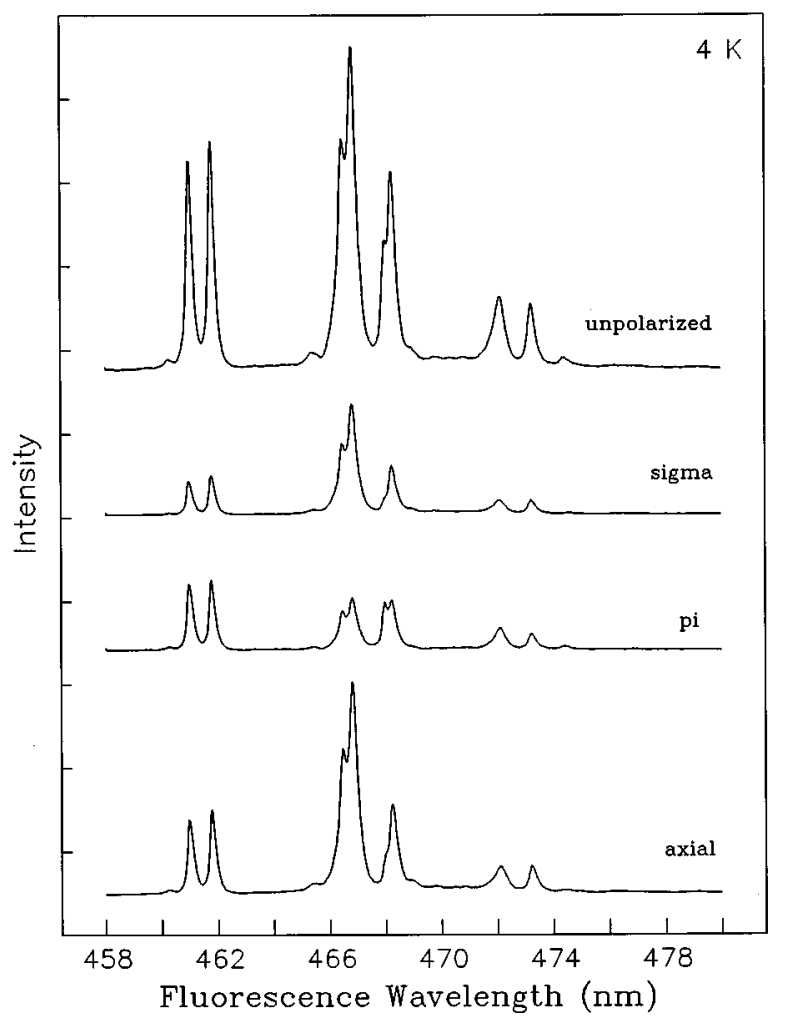

FIG. 8. Polarized emission spectra (transverse and axial) from the ${ }^{1} D_{2}$ to the ${ }^{3} \mathrm{~F}_{4}$ multiplet manifold at $4 \mathrm{~K}$.

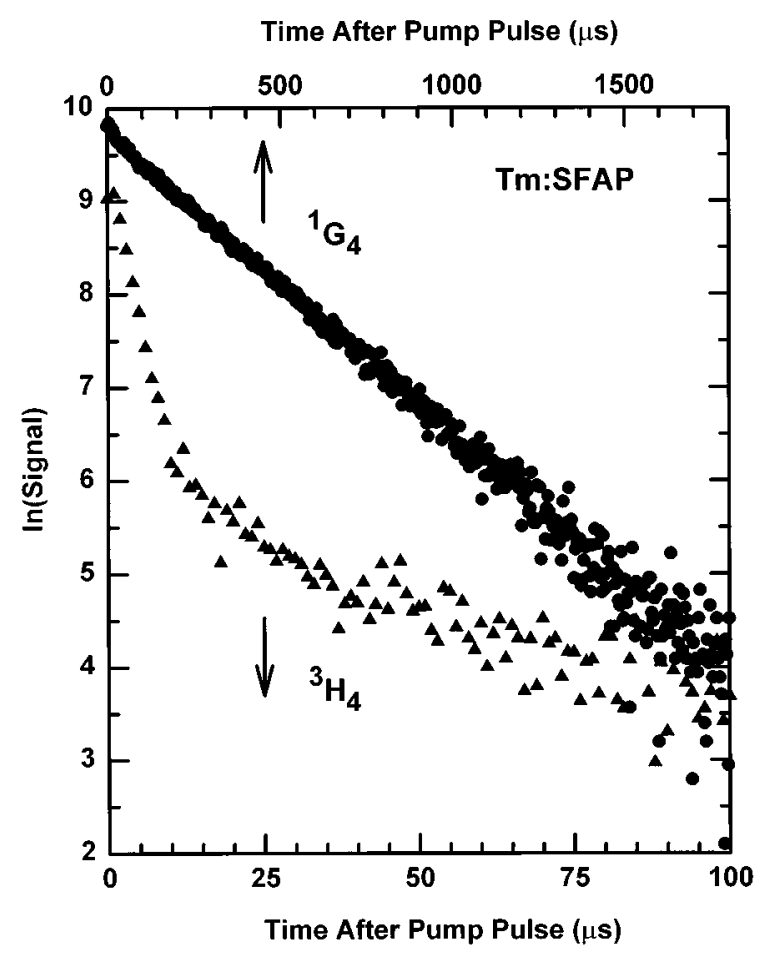

FIG. 9. Room temperature fluorescence decay waveforms for Tm:SFAP ${ }^{1} \mathrm{G}_{4}$ and ${ }^{3} \mathrm{H}_{4}$ fluorescence following pulsed excitation. The upper time scale applies to the ${ }^{1} \mathrm{G}_{4}$ decay, the lower scale to the ${ }^{3} \mathrm{H}_{4}$ decay. 
TABLE VI. Crystal-field components and parameters for $\mathrm{Tm}^{3+}$ and $\mathrm{Er}^{3+}$ in SFAP (sites of $C_{s}$ symmetry). ${ }^{\text {a }}$

\begin{tabular}{|c|c|c|c|c|c|}
\hline$A_{n m}$ & $\left(\mathrm{~cm}^{-1} / \AA^{n}\right)$ & $B_{n m}$ & $\begin{array}{c}\mathrm{Tm}^{3+}\left(\mathrm{cm}^{-1}\right) \\
\text { final }\end{array}$ & $\begin{array}{c}\mathrm{Er}^{3+}\left(\mathrm{cm}^{-1}\right) \\
\text { predicted }\end{array}$ & $\begin{array}{c}\mathrm{Er}^{3+}\left(\mathrm{cm}^{-1}\right) \\
\text { final }\end{array}$ \\
\hline$A_{20}$ & 11057 & $B_{20}$ & 2009 & 1886 & 1882 \\
\hline$A_{22}$ & 657 & $B_{22}$ & 295 & 112 & 28.7 \\
\hline$A_{40}$ & 2053 & $B_{40}$ & 876 & 1177 & 1462 \\
\hline $\operatorname{Re} A_{42}$ & 455 & $\operatorname{Re} B_{42}$ & 204 & 188 & 261 \\
\hline $\mathrm{I} A_{42}$ & -1861 & $\mathrm{I} B_{42}$ & -934 & -768 & -784 \\
\hline $\operatorname{Re} A_{44}$ & 524 & $\operatorname{Re} B_{44}$ & 124 & 216 & -41.2 \\
\hline $\mathrm{I} A_{44}$ & 764 & $\mathrm{I} B_{44}$ & 536 & 315 & 99.0 \\
\hline$A_{60}$ & 288 & $B_{60}$ & 434 & 283 & -158 \\
\hline $\operatorname{Re} A_{62}$ & -48 & $\operatorname{Re} B_{62}$ & -122 & -47 & -76.3 \\
\hline $\mathrm{I} A_{62}$ & -267 & $\mathrm{I} B_{62}$ & $-\quad 26.8$ & -262 & -147 \\
\hline $\operatorname{Re} A_{64}$ & -289 & $\operatorname{Re} B_{64}$ & -185 & -284 & -324 \\
\hline $\mathrm{I} A_{64}$ & 38.0 & $\mathrm{I} B_{64}$ & -141 & 37.0 & 341 \\
\hline $\operatorname{Re} A_{66}$ & 117 & $\operatorname{Re} B_{66}$ & 47.5 & 115 & 141 \\
\hline $\mathrm{I} A_{66}$ & -1147 & $\mathrm{I} B_{66}$ & -1601 & -1127 & -438 \\
\hline
\end{tabular}

"In the table "Re' denotes real and "I'" denotes imaginary.

axis, $B_{22}$ is made real and positive thus reducing the number of parameters to $14 .^{29}$ The $B_{n m}$ are related to the crystal-field components, $A_{n m}$, by the expression,

$$
B_{n m}=\rho_{n} A_{n m}
$$

where

$$
A_{n m}=-\mathrm{e}^{2} \sum_{j} q_{j} C_{n m}\left(\hat{R}_{j}\right) / R_{j}^{n+1} .
$$

In Eq. (4) $\rho_{n}$ represents the effective value of $\left\langle r^{n}\right\rangle$ associated with the monopole $A_{n m}$. In Eq. (5) the effective charge is $q_{j}$ on the ion at $\hat{R}_{j}$, and the sum is taken over all ions in the lattice. ${ }^{31-33}$ The $A_{n m}$ components were calculated for the $\mathrm{M}(\mathrm{II})$ site $\left(C_{s}\right.$ symmetry) using the x-ray data reported for

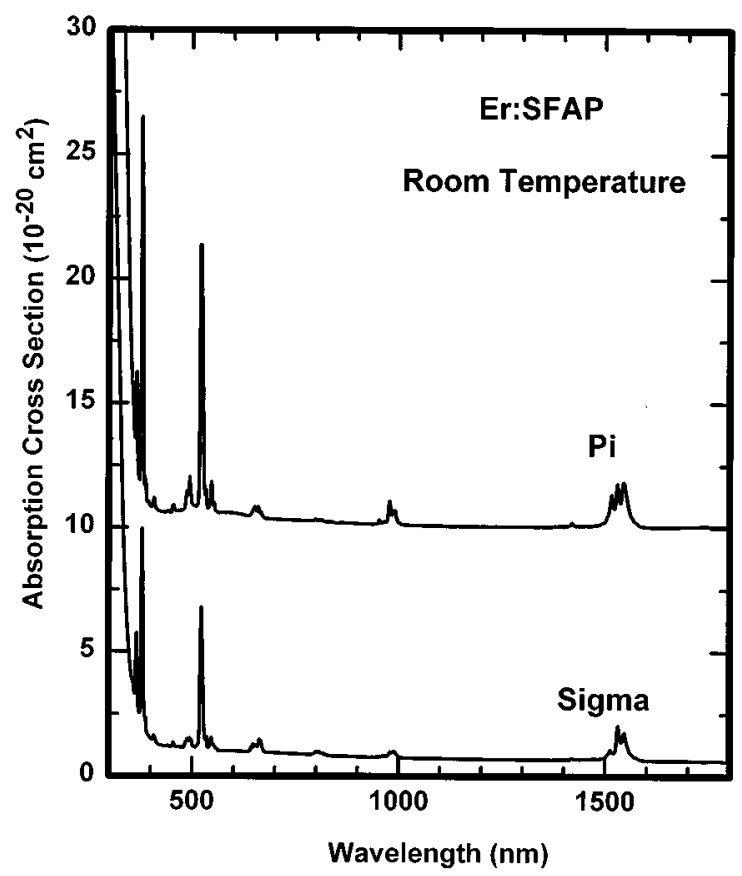

FIG. 10. Room temperature absorption spectrum of Er:SFAP.

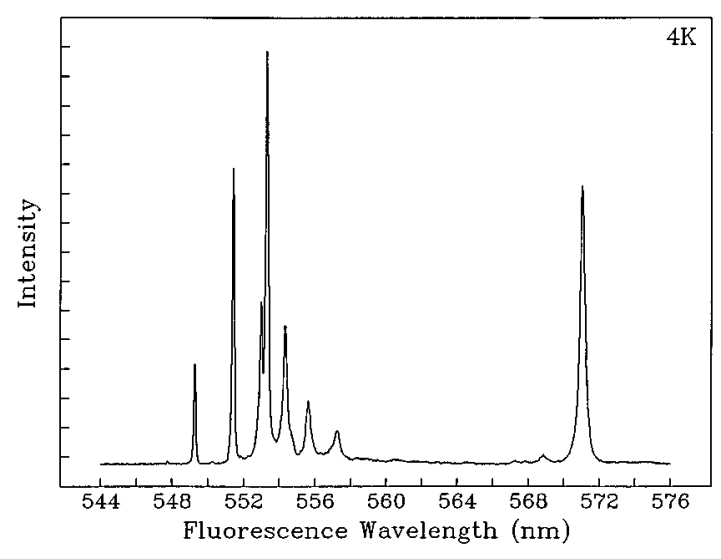

FIG. 11. Fluorescence from the ${ }^{4} S_{3 / 2}$ to the ${ }^{4} I_{15 / 2}$ multiplet manifold observed at $4 \mathrm{~K}$.

SFAP. ${ }^{18,22}$ The effect of replacing the nearest $\mathrm{F}^{-}$site by an $\mathrm{O}^{2-}$ site was obtained by calculating the $A_{n m}$ for a negative charge at this site and adding these components to the $A_{n m}$ components for the $\mathrm{M}(\mathrm{II})$ site without charge compensation. ${ }^{18}$ A value of $q=-2.00$ for the oxygen charge was chosen.

Using the calculated $B_{n m}$ parameters in the crystal-field splitting calculations, we obtained predicted Stark levels with symmetry labels that are consistent with conclusions obtained from experiment. The predicted ground-state Stark level and the first excited Stark level were several wavenumbers apart and of different symmetry (consistent with experimental results reported in Tables II and III. The splitting of the two lowest energy Stark levels in ${ }^{3} \mathrm{H}_{5}$ were also predicted to be of different symmetry and separated by several wavenumbers. The experimental assignments for these levels are $8209\left(\Gamma_{2}\right)$ and $8212 \mathrm{~cm}^{-1}\left(\Gamma_{1}\right)$ in Table II and $8208\left(\Gamma_{2}\right)$ and $8212 \mathrm{~cm}^{-1}\left(\Gamma_{1}\right)$ in Table III. These assignments are based on some of the strongest fluorescence observed. The predicted symmetry label for the emitting Stark level in the ${ }^{1} \mathrm{D}_{2}$ and ${ }^{1} \mathrm{G}_{4}$ manifolds give polarization patterns consistent with experiment.

Not all Stark levels of ${ }^{3} \mathrm{H}_{6}$ were observed. Because of the size of the crystal-field splitting, the $J$-mixing between multiplet manifolds ${ }^{3} \mathrm{H}_{6}$ and ${ }^{3} \mathrm{~F}_{4}$ affects the splitting of the ${ }^{3} \mathrm{~F}_{4}$ manifold. The $5677 \mathrm{~cm}^{-1}\left(\Gamma_{1}\right)$ Stark level in particular appears to be affected by Stark levels not identified in the ${ }^{3} \mathrm{H}_{6}$ manifold. While the predicted value for the $5677 \mathrm{~cm}^{-1}$ level is close to a weaker absorption peak observed at $5717 \mathrm{~cm}^{-1}$ in Table I, the latter does not appear in fluorescence. Consistent analysis of the fluorescence spectra matches the stronger absorption peak at $5677 \mathrm{~cm}^{-1}$ to a level observed in fluorescence.

Numerous least-squares fitting routines were used to maximize agreement between all experimental Stark levels identified from the polarized fluorescence spectra and calculated Stark levels whose energy as well as symmetry label most closely agree with experiment. The list of experimental levels was then expanded to include the most intense peaks observed in absorption. The best overall agreement obtained between calculated and experimental Stark levels is repre- 
sented by the calculated splitting appearing in Tables I-III in which an rms deviation of $7 \mathrm{~cm}^{-1}$ was obtained between 43 calculated and observed levels. Because of the large crystal field, Table I also includes the percent of free-ion mixture. The final set of $B_{n m}$ parameters for $\mathrm{Tm}^{3+}$ in Tm:SFAP is given in Table VI.

\section{ANALYSIS OF THE Er:SFAP SPECTRA AND FLUORESCENCE LIFETIME MEASUREMENTS}

Table IV presents the absorption spectrum of Er:SFAP obtained at $4 \mathrm{~K}$. A room temperature survey spectrum is given in Fig. 10. Both spectra are distinguished by having $J+1 / 2$ relatively strong absorption speaks associated with each multiplet manifold of $\operatorname{Er}^{3+}\left(4 f^{11}\right)$. In addition to these strong peaks, much weaker and usually broad peaks, many appearing as satellite peaks to the strong peaks, are observed in the absorption spectrum and are attributable to $\mathrm{Er}^{3+}$ ions in minority sites in SFAP. The spectrum appearing in Table IV is much simpler than the absorption spectrum for $\mathrm{Er}^{3+}$ ions in Er:FAP reported by Gruber et al. ${ }^{11}$ In $C_{s}$ symmetry all Stark levels for $\mathrm{Er}^{3+}$ have the same symmetry label, ${ }^{2} \Gamma_{6}$, and transitions in both $\sigma$ - and $\pi$-polarization are allowed between these levels without restriction. The intensities of individual transitions appearing in the axial spectrum at $4 \mathrm{~K}$ are listed in Table IV (col. 3).

Fluorescence spectra from the ${ }^{4} \mathrm{~S}_{3 / 2}$ multiplet manifold to the ground-state manifold, ${ }^{4} \mathrm{I}_{15 / 2}$, are reported in Table $\mathrm{V}$ and are displayed in Fig. 11. We were not able to completely reduce the emission to a single site, as a second site is apparent, having comparable splitting, as evidenced by a weaker emission spectrum that is nearly superimposed on the emission attributed to $\mathrm{Er}^{3+}$ ions in the majority site. Measurement of the temporal decay of the room temperature fluorescence from the ${ }^{4} \mathrm{I}_{11 / 2}$ and ${ }^{4} \mathrm{I}_{13 / 2}$ manifolds yields fluorescence lifetimes of $230 \pm 20 \mu \mathrm{s}$ and $8.9 \pm 0.1 \mathrm{~ms}$, respectively. These data are uncorrected for reabsorption effects, as reabsorption is considered to be minimal due to the dilution of the samples and the low absorption cross-sections. The lifetimes are somewhat shorter than were observed for erbium in FAP, ${ }^{11}$ possibly indicating the presence of nonradiative relaxation channels in SFAP that are not present in FAP, though larger radiative transition probabilities may also contribute to the lifetime shortening.

Irradiation of the nominally $1 \%$ Er:SFAP sample with the $978 \mathrm{~nm}$ diode array at a fluence of greater than $1.2 \mathrm{~kW} / \mathrm{cm}^{2}$ produced no upconversion emission from the ${ }^{4} S_{3 / 2}$ manifold, indicating that cross relaxation between ions excited into the ${ }^{4} \mathrm{I}_{11 / 2}$ manifold is not a dominant relaxation path.

The crystal-field splitting analysis of Er:SFAP was carried out by deriving a set of $B_{n m}$ parameters for $\mathrm{Er}^{3+}$ ions from the final set of $B_{n m}$ parameters obtained for $\mathrm{Tm}^{3+}$ that are listed in Table VI. The predicted set of $B_{n m}$ parameters for $\mathrm{Er}^{3+}$ were calculated using the $A_{n m}$ crystal-field components appearing in Table VI and the values of $\rho_{n}$ obtained from Ref. 32. The Stark levels obtained from the $J+1 / 2$ strong absorption peaks associated with each multiplet manifold of $\mathrm{Er}^{3+}$ in Er:SFAP reported in Table IV were compared with the calculated levels using the predicted $B_{n m}$ parameters for $\mathrm{Er}^{3+}$. With modest change to most predicted $B_{n m}$ parameters we were able to obtain a final rms deviation of $7 \mathrm{~cm}^{-1}$ between 43 experimental and calculated levels. The final set of $B_{n m}$ parameters for $\mathrm{Er}^{3+}$ appears in column 6 of Table VI. Examination of the spectra reported in Table IV indicates that the $J+1 / 2$ absorption peaks used in our analysis represent more than $95 \%$ of the total absorption by all $\mathrm{Er}^{3+}$ ions in the crystal. The majority of $\mathrm{Er}^{3+}$ ions occupy a site of $C_{s}$ symmetry. The free-ion mixture is also given in Table IV since the relatively large crystal-field splitting mixes states of adjacent manifolds to some extent, e.g., ${ }^{4} \mathrm{~F}_{5 / 2}$ and ${ }^{4} \mathrm{~F}_{3 / 2}$.

\section{CONCLUSIONS}

From an analysis of the absorption and site-selective polarized fluorescence data, we conclude that the majority of $\mathrm{Tm}^{3+}$ and $\mathrm{Er}^{3+}$ ions occupy sites of $C_{s}$ symmetry. Results support the conclusion that $\mathrm{Tm}^{3+}$ and $\mathrm{Er}^{3+}$ ions substitute for $\mathrm{Sr}^{2+}$ at the $\mathrm{M}(\mathrm{II})$ site in the undoped lattice. The nearestneighbor fluoride $\left(\mathrm{F}^{-}\right)$is replaced by divalent oxygen $\left(\mathrm{O}^{2-}\right)$ thus preserving overall charge neutrality and local $C_{s}$ symmetry. The crystal-field splitting of individual multiplet manifolds represents some of the largest splittings observed for these ions in insulator host crystals. Consequently, $J$-mixing is relatively larger for certain manifolds (see for example, ${ }^{4} \mathrm{~F}_{\mathrm{J}}$, Er:SFAP, Table IV). Larger $J$-mixing also affects the oscillator strengths that represent the intensities of the absorption and fluorescence spectra.

Absorption transitions from the ground-state to excited Stark levels within a given manifold exhibit a greater range of individual intensities than found for comparable transitions of the same ion in other low symmetry host crystals. For example, of the $J+1 / 2$ Stark level transitions allowed from the ground-state to the ${ }^{4} \mathrm{I}_{13 / 2}$ manifold in Er:SFAP, two of seven allowed transitions represent more than $90 \%$ of the absorption to this manifold at $4 \mathrm{~K}$. Hot band absorption in both Tm:SFAP and Er:SFAP is very weak in comparison with the hot band absorption spectra observed in Tm:YAG ${ }^{34}$ and Er:YAG. ${ }^{35}$

Due to the moderately long ${ }^{4} \mathrm{I}_{11 / 2}$ fluorescence lifetime in Er:SFAP, $(230 \pm 20 \mu \mathrm{s}$, room temperature) this material will probably not make a good host for $\mathrm{Yb}$ to Er-sensitized 1.5 $\mu \mathrm{m}$ laser action, as the energy transfer to the erbium from the ytterbium would be inefficient. Direct pumping into the ${ }^{4} \mathrm{I}_{13 / 2}$ manifold to obtain $1.5 \mu \mathrm{m}$ laser action would be difficult, as most of the oscillator strength is concentrated between the lowest Stark levels of the two manifolds. The long ${ }^{4} \mathrm{I}_{11 / 2}$ lifetime, in conjunction with the uneven distribution of oscillator strength for transitions between the ${ }^{4} \mathrm{I}_{11 / 2}$ and ${ }^{4} \mathrm{I}_{13 / 2}$ manifolds, may prove to be sufficient for development of an efficient $2.8 \mu \mathrm{m}$ laser source. ${ }^{14}$

The large oscillator strength of the transition from the ground Stark level in ${ }^{4} \mathrm{I}_{15 / 2}$ to the lowest Stark level within the ${ }^{4} I_{13 / 2}$ manifold in Er:SFAP indicates that this material may function as a passive Q-switch for erbium glass lasers operating at $1.53 \mu \mathrm{m} .{ }^{3,9}$ However, the long ${ }^{4} \mathrm{I}_{13 / 2}$ lifetime $(8.9 \pm 0.1 \mathrm{~ms})$ means that the Q-switch would probably re- 
main transparent, allowing free-running lasing to occur after the generation of the Q-switched pulse.

${ }^{1}$ J. B. Gruber, C. A. Morrison, M. D. Seltzer, A. O. Wright, M. P. Nadler, T. H. Allik, J. A. Hutchinson, and B. H. T. Chai, J. Appl. Phys. 79, 1746 (1996).

${ }^{2}$ L. D. De Loach, S. A. Payne, L. L. Chase, L. K. Smith, W. L. Kway, and W. F. Krupke, IEEE J. Quantum Electron. QE-29, 1179 (1993).

${ }^{3}$ J. B. Gruber and M. D. Seltzer, Modeling of Saturable Q-switch Absorbers, in Proceedings of the IEEE/LEOS Eighth Annual Meeting, San Francisco, CA, 1995 (unpublished), p. 54.

${ }^{4}$ A. O. Wright, M. D. Seltzer, J. B. Gruber, B. Zandi, L. D. Merkle, and B. H. T. Chai, J. Phys. Chem. Solids 57, 1337 (1996).

${ }^{5}$ J. B. Gruber, J. A. Hutchinson, D. C. Harris, M. D. Seltzer, T. H. Allik, C. A. Morrison, and M. P. Scripsick, Materials Research Society Symposium Proceedings, edited by B. H. T. Chai, S. A. Payne, T. Y. Fan, and T. H. Allik (Materials Research Society, Pittsburgh, PA, 1994), Vol. 329, p. 209.

${ }^{6}$ L. D. De Loach, S. A. Payne, W. L. Kway, J. B. Tassano, S. N. Dixit, and W. F. Krupke, J. Lumin. 62, 85 (1994).

${ }^{7}$ B. H. T. Chai, Novel Laser Sources and Applications, edited by J. F. Becker, A. C. Tam, J. B. Gruber, and L. Lam (SPIE, Bellingham, WA, 1994), p. 5

${ }^{8}$ A. O. Wright, M. D. Seltzer, J. B. Gruber, and B. H. T. Chai, J. Appl. Phys. 78, 2456 (1995)

${ }^{9}$ T. H. Allik, J. B. Gruber, M. D. Seltzer, M. E. Hills, K. Spariosu, R. D. Stultz, M. Birnbaum, C. A. Morrison, B. H. T. Chai, J. A. Hutchinson, and L. D. Merkle, OSA Proceedings on Advanced Solid-State Lasers, edited by L. L. Chase and A. A. Pinto (Optical Society of America, Washington DC, 1993), Vol. 15, p. 246.

${ }^{10}$ P. Hong, X. X. Zhang, R. E. Peale, H. Weidner, M. Bass, and B. H. T. Chai, J. Appl. Phys. 77, 294 (1995).

${ }^{11}$ J. B. Gruber, M. D. Seltzer, M. E. Hills, T. H. Allik, J. A. Hutchinson, C. A. Morrison, and B. H. T. Chai, Opt. Mater. 3, 99 (1994).

${ }^{12}$ R. C. Ohlmann, K. B. Steinbruegge, and R. Mazelsky, Appl. Opt. 7, 905 (1968).

${ }^{13}$ F. M. Ryan, R. W. Warren, R. H. Hopkins, and J. Murphy, J. Electrochem. Soc. Solid State Sci. 125, 1493 (1978).

${ }^{14}$ J. B. Gruber, Tunable Lasers for Engineering and Biological Applications (SPIE, Bellingham, WA, 1992).

${ }^{15}$ G. V. Maksimova and A. A. Sobol', Inorg. Mater. 8, 945 (1972).

${ }^{16}$ G. V. Maksimova and A. A. Sobol', Tr. Fiz. Inst. Akad. Nauk SSSR 60, 55 (1972).
${ }^{17}$ G. V. Maksimova and A. A. Sobol', Proc. P. N. Lebedev Phys. Inst. 60, 59 (1974)

${ }^{18}$ C. A. Morrison, Point-Charge Analysis of Symmetry-Preserving Charge Compensation and Vacacies in the Fluorapatites $\mathrm{Ca}_{5}\left(\mathrm{PO}_{4}\right)_{3} \mathrm{~F}$ and $\mathrm{Sr}_{5}\left(\mathrm{PO}_{4}\right)_{3} \mathrm{~F}$, Army Research Laboratory Report. ARL-TR-703, Adelphi, MD 20783, June, 1995.

${ }^{19}$ M. E. Fleet and Y. M. Pan, J. Solid State Chem. 112, 78 (1994).

${ }^{20}$ St. Narcy-Szabo, Z. Kristallogr. 75, 387 (1930).

${ }^{21}$ R. W. Wyckoff, Cryst. Struct. 3, 228 (1965).

${ }^{22}$ J. M. Hughes, M. Cameron, and K. D. Crowley, Am. Mineral. 74, 870 (1989).

${ }^{23}$ M. Greenblatt and J. H. Pifer, J. Chem. Phys. 66, 559 (1977).

${ }^{24}$ W. W. Piper, L. C. Kravitz, and R. K. Swank, Phys. Rev. A 138, 1802 (1965).

${ }^{25}$ H. A. Bethe, Ann. Phys. (Leipzig) 3, 133 (1929).

${ }^{26}$ J. L. Prather, Atomic Energy Levels in Crystals, NBS Monograph 19 (U.S. Department of Commerce, National Bureau of Standards, Washington D.C., 1961).

${ }^{27}$ C. Li, A. Lagriffoul, R. Moncorgé, J. C. Souriau, C. Borel, and Ch. Wyon, J. Lumin. 62, 157 (1994).

${ }^{28}$ G. H. Rosenblatt, G. J. Quarles, L. Esterowitz, M. Randles, J. Creamer, and R. Belt, Opt. Lett. 18, 1523 (1993).

${ }^{29}$ L. D. Merkle, B. Zandi, and B. H. T. Chai, Spectroscopic Evaluation of the Visible Laser Potential of Several $\mathrm{Pr}^{3+}$ and $\mathrm{Tm}^{3+}$ Doped Crystals, OSA Trends in Optics and Photonics on Advanced Solid State Lasers, edited by S. A. Payne and C. R. Pollack (Optical Society of America, Washington, DC, 1996), Vol. 1, pp. 516-521.

${ }^{30}$ W. T. Carnall, P. R. Fields, and K. Rajnak, J. Chem. Phys. 49, 4412 (1968); 49, 4424 (1968); 49, 4443 (1968); 49, 4450 (1968).

${ }^{31}$ C. A. Morrison and R. P. Leavitt, J. Chem. Phys. 71, 2366 (1979).

${ }^{32}$ C. A. Morrison, Angular Momentum Theory Applied to Interactions in Solids, Lecture Notes in Chemistry (Springer-Verlag, New York, 1988), Vol. 47.

${ }^{33}$ C. A. Morrison, Crystal Fields for Transition-Metal Ions in Laser Host Materials (Springer-Verlag, New York, 1992).

${ }^{34}$ J. B. Gruber, M. E. Hills, R. M. Macfarlane, C. A. Morrison, G. A. Turner, G. J. Quarles, G. J. Kintz, and L. Esterowitz, Phys. Rev. B 40, 9464 (1989).

${ }^{35}$ J. B. Gruber, J. R. Quagliano, M. F. Reid, F. S. Richardson, M. E. Hills, M. D. Seltzer, S. B. Stevens, C. A. Morrison, and T. H. Allik, Phys. Rev. B 48, 15-56 (1993). 